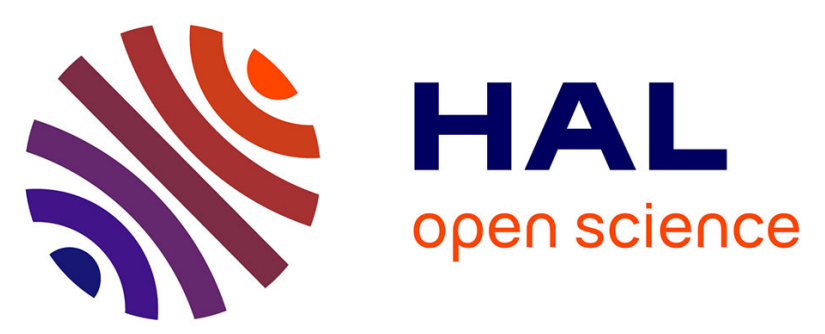

\title{
Size-Resolved Dry Deposition Velocities of Dust Particles: In Situ Measurements and Parameterizations Testing
}

G. Bergametti, B. Marticoréna, J. L Rajot, Gilles Foret, S. Alfaro, B. Laurent

\section{- To cite this version:}

G. Bergametti, B. Marticoréna, J. L Rajot, Gilles Foret, S. Alfaro, et al.. Size-Resolved Dry Deposition Velocities of Dust Particles: In Situ Measurements and Parameterizations Testing. Journal of Geophysical Research: Atmospheres, 2018, 123 (19), pp.11,080-11,099. 10.1029/2018JD028964 . hal-02323364

\section{HAL Id: hal-02323364 \\ https://hal.science/hal-02323364}

Submitted on 21 Oct 2019

HAL is a multi-disciplinary open access archive for the deposit and dissemination of scientific research documents, whether they are published or not. The documents may come from teaching and research institutions in France or abroad, or from public or private research centers.
L'archive ouverte pluridisciplinaire HAL, est destinée au dépôt et à la diffusion de documents scientifiques de niveau recherche, publiés ou non, émanant des établissements d'enseignement et de recherche français ou étrangers, des laboratoires publics ou privés. 


\section{Journal of Geophysical Research: Atmospheres}

\section{RESEARCH ARTICLE}

10.1029/2018JD028964

Key Points:

- A dust deposition event allows the determination of dust deposition fluxes and dry deposition velocities using the flux gradient method

- The time evolution of dry deposition velocities is mainly controlled by the wind friction velocity and, for large particles, by rebound

- Measured dry deposition velocities are in better agreement with parameterizations that consider bare sandy surfaces as rough surfaces

Supporting Information:

- Supporting Information S1

- Movie S1

Correspondence to:

G. Bergametti,

gilles.bergametti@lisa.u-pec.fr

Citation:

Bergametti, G., Marticorena, B. Rajot, J. L., Foret, G., Alfaro, S. C., \& Laurent, B. (2018). Size-resolved dry deposition velocities of dust particles: In situ measurements and parameterizations testing. Journal of Geophysical Research: Atmospheres, 123 11,080-11,099. https://doi.org/10.1029/ 2018JD028964

Received 7 MAY 2018

Accepted 31 AUG 2018

Accepted article online 6 SEP 2018

Published online 2 OCT 2018

C2018. American Geophysical Union. All Rights Reserved.

\section{Size-Resolved Dry Deposition Velocities of Dust Particles: In Situ Measurements and Parameterizations Testing}

\author{
G. Bergametti $^{1}$ iD, B. Marticorena ${ }^{1}$ iD, J. L. Rajot ${ }^{1,2,3}$ iD, G. Foret ${ }^{1}$, S. C. Alfaro ${ }^{1}$, and B. Laurent ${ }^{1}$ \\ ${ }^{1}$ Laboratoire Interuniversitaire des Systèmes Atmosphériques, UMR CNRS 7583, Université Paris-Est Créteil and Université \\ Paris-Diderot, Institut Pierre-Simon Laplace, Paris, France, ${ }^{2}$ Institut d'Ecologie et des Sciences de I'Environnement de Paris, \\ UMR IRD 242, Université Pierre et Marie Curie-CNRS-INRA-Université Paris Est Créteil-Université Paris Diderot, Paris, \\ France, ${ }^{3}$ Institut des Régions Arides, Médenine, Tunisia
}

Abstract Bulk and size-resolved particle concentrations were measured at 2.1 and $6.5 \mathrm{~m}$ above the soil surface during an intense dust deposition event that occurred in June 2006 in Niger. Bulk concentration measurements were performed using two tapered element oscillating microbalance instruments, and the size-resolved particle concentrations (from 0.3 to $20 \mu \mathrm{m}$ ) using two optical particle counters. The deposition fluxes derived from the bulk concentrations and those derived from the size-resolved ones are in very good agreement. The largest deposition fluxes are recorded when the dust concentrations are maximal. The temporal evolution of the dust deposition flux follows that of the dust concentration. This is not the case of the dry deposition velocities that are most of the time controlled by the wind friction velocity. The results also show that large particles are strongly sensible to rebound when the wind friction velocity is the highest. Size-resolved dry deposition velocities are compared with the rare measurements of dust deposition velocities over bare sandy soils and are confronted to existing parameterizations of the dry deposition velocity. The parameterization of Zhang and Shao (2014, https://doi.org/10.5194/acp-14-12429-2014) appears to be the only one able to reproduce satisfyingly the measured dry deposition velocities on sandy soils in the 1- to $10-\mu \mathrm{m}$ particle size range. Indeed, unlike others, this scheme considers the desert sandy surfaces as rough surfaces, allowing the interception of dust particles by the sand grains and/or by the small roughness elements present on the surface.

\section{Introduction}

Wet and dry deposition are the only processes able to remove air-suspended dust particles from the atmosphere. However, dry deposition is the predominant deposition process for dust due to its mass-size distribution dominated by large particles and to the scarcity of precipitation in the source regions as well as along its main transport routes. By comparing simulations performed with seven dust models, the AEROCOM (AEROsol interComparison) project suggested that dry deposition contributes $65-80 \%$ of the total dust deposition (Textor et al., 2007). A precise quantification of this sink is thus necessary to constrain the mass budget in dust transport models (e.g., Bergametti \& Foret, 2014).

Most deposition data reported in the literature correspond to direct deposition measurements performed with collectors that separate, or not, wet from dry deposition. These data when acquired over a long period of time (e.g., Bergametti et al., 1989; Heimburger et al., 2013; Loÿe-Pilot \& Martin, 1996; Marticorena et al., 2017; Prospero et al., 2010; Uetmatsu et al., 1985; Vincent et al., 2016) provide information on the seasonality and on the orders of magnitude of dust deposition fluxes but rarely on the size of the deposited dust. They allow comparisons with the deposition simulated by dust transport models over periods ranging from 1 week to months. However, although a large fraction of the emitted dust mass is dry deposited along the first 1,000 km of transport (e.g., Schütz, 1979), only a limited number of deposition measurements were performed close to the dust source regions (for more details, see Marticorena et al., 2017, and references therein). In addition, very few of these measurements provided relevant information on the dust dry deposition only mainly because of the technical difficulties one must overcome to perform these direct measurements. Indeed, inertial impaction and interception are, with gravitational settling, the key processes controlling the deposition of large particles, and the efficiency of these processes depends strongly on the characteristics of the collecting surface. Unfortunately, the dry collection vessels of the measurement networks are far from being able to mimic correctly the microscale roughness features of 
the most frequent (bare soil, grassland, forest, or water) real deposition surfaces (e.g., Goossens, 2010; Sow et al., 2006).

In dust transport models, dry deposition is typically calculated from a combination of dry deposition velocities and particle size distributions but, as mentioned by Huneeus et al. (2011), "such estimates are prone to large uncertainties which are typically quoted as plus/minus a factor of three (Duce et al., 1991) but which could well be larger." Most of the dry deposition parameterizations currently used in transport models (e.g., Davidson \& Friedlander, 1978; Giorgi, 1986; Petroff \& Zhang, 2010; Slinn, 1982; Wesely et al., 1985; Zhang et al., 2001; Zhang \& He, 2014; Zhang \& Shao, 2014) are based on deposition data obtained in wind tunnel experiments. Indeed, until recently, field experiments allowing the comparison of dry deposition velocity parameterizations with actual in situ data were rare. Ideally, the most efficient method to derive dust dry deposition velocities from in situ measurements would be the eddy correlation technique (e.g., Businger, 1986). It requires measurements of the dust concentration at a frequency large enough $(>1 \mathrm{~Hz})$ to separate the turbulent fluctuations of the concentration from the mean value. Unfortunately, most of the instruments currently able to measure particle concentrations at such a frequency are efficient in a size range limited to particles smaller than 1-2 $\mu \mathrm{m}$ in diameter and the deposition velocities derived from this method generally concern only the submicron particle sizes. Moreover, most of the dry deposition velocities derived from the eddy correlation technique were obtained over more or less vegetated surfaces (e.g., Fowler et al., 2009; Petroff et al., 2008). The first attempts to apply such methods to the dry deposition of dust in semiarid regions were those of Porch and Gillette (1977) in Texas and those of Lamaud et al. (1994) in Niger, but again both remained limited to particles in the $\sim 0.1$ - to 1 - $\mu$ m particle size range.

The alternative to eddy correlation methods consists in using the flux gradient method. The main difficulty with this method consists in measuring the particle concentrations at different heights with a sufficient accuracy because the concentration gradient may be very low (Businger, 1986). This explains why the gradient method was rather used for measuring dust emission fluxes, this type of situations producing generally stronger concentration gradients (e.g., Gillette, 1977; Nickling \& Gillies, 1989; Sow et al., 2009) than deposition events.

In this paper, we use data obtained in Niger in June 2006 during a deposition event to determine the dry deposition flux of dust particles. This event was huge and consecutive to dust emission occurring only $12 \mathrm{hr}$ before, providing the opportunity to measure large concentration gradients in different size classes and discuss the role of the different factors in controlling the dust deposition flux and the dry deposition velocity. We then compare the dry deposition velocities derived from our measurements with the ones simulated using two dry deposition parameterizations based on different approaches (Zhang et al., 2001; Zhang \& Shao, 2014).

\section{Background on Dry Deposition Concepts and Modeling}

Different physical processes interact for controlling the dry deposition of dust particles. Among these processes, gravitational settling, turbulent diffusion, and surface collection are generally the most important, and their effects are usually accounted for by the means of equivalent resistances (gravitational resistance, aerodynamic resistance, and surface collection resistance, respectively) that oppose to the deposition.

Gravitational settling is a process operating as long as a particle remains air-suspended and depends mainly on the size and density of particles. A particle falling freely in still air is subject to gravity and aerodynamic drag forces: When these forces are in equilibrium, the particle reaches the so-called particle terminal velocity or gravitational settling velocity that is given by Stokes formula:

$$
V_{\mathrm{s}}=\frac{d_{\mathrm{p}}^{2}\left(\rho_{\mathrm{p}}-\rho_{\mathrm{a}}\right) g C u}{18 \mu_{\mathrm{a}}}
$$

where $d_{\mathrm{p}}$ (in $\mathrm{m}$ ) is the particle diameter; $\rho_{\mathrm{p}}$ and $\rho_{\mathrm{a}}$ (in $\mathrm{kg} / \mathrm{m}^{3}$ ) are the particle and air densities, respectively; $g$ is the gravity acceleration (in $\mathrm{m} / \mathrm{s}^{2}$ ); $\mu_{\mathrm{a}}$ (in $\mathrm{kg} \cdot \mathrm{m}^{-1} \cdot \mathrm{s}^{-1}$ ) is the air dynamic viscosity; and $\mathrm{Cu}$ is the Cunningham correction factor that accounts for the slipping effect affecting the finest particles, especially the submicron ones: 


$$
C u=1+\left(\frac{2 \lambda_{\mathrm{a}}}{d_{\mathrm{p}}}\right)\left(1.257+0.4 \exp \left(-0.55^{d_{\mathrm{p}}} / \lambda_{\mathrm{a}}\right)\right)
$$

where $\lambda_{\mathrm{a}}$ (in $\mathrm{m}$ ) is the air mean free path:

$$
\lambda_{\mathrm{a}}=2 \mu_{\mathrm{a}}(P \sqrt{8 / \pi R T})
$$

where $R$ (in $\mathrm{J} \cdot \mathrm{K}^{-1} \cdot \mathrm{kg}^{-1}$ ) is the gas constant, $T$ (in $\mathrm{K}$ ) is the temperature, and $P$ (in $\mathrm{Pa}$ ) is the pressure.

When a particle approaches a surface, an aerodynamic resistance and a surface resistance add their effects to the gravitational settling for controlling its dry deposition. The current dry deposition parameterizations mostly differ in the way these resistances, particularly the surface one, are parameterized.

The aerodynamic resistance, $r_{\mathrm{a}}$, depends on the characteristics of the flow in the atmospheric surface layer. Theoretically, in neutral conditions (i.e., no vertical gradient of potential air temperature), for a steady state and horizontally homogeneous flow and for a given surface, a simple similarity hypothesis allows the description of the vertical distribution of the wind velocity. The vertical gradient of the wind velocity $d u / d z$ is assumed to depend only on the height, $z$, above the surface as described by a log law (e.g., Panofsky \& Dutton, 1984), for $z \gg z_{0}$ :

$$
u_{(z)}=u_{*} / k \ln \left(\frac{z}{z_{0}}\right)
$$

where $u_{(z)}$ is the averaged horizontal component of the wind velocity (in $\mathrm{m} / \mathrm{s}$ ) measured at height $z$ (in $\mathrm{m}$ ), $u_{*}$ is the wind friction velocity (in $\mathrm{m} / \mathrm{s}$ ), $z_{0}$ is the aerodynamic roughness length (in $\mathrm{m}$ ), and $k$ is the von Karman constant. The precise value of this constant is still in debate but is generally taken as 0.4 (e.g., Foken, 2006).

A quite general expression of $r_{\mathrm{a}}$ has been proposed by Zhang and Shao (2014) for smooth surface and neutral stability conditions:

$$
r_{\mathrm{a}}(z)=\frac{C S c}{k u_{*}} \ln \left(\frac{z}{z_{0}}\right)
$$

where $S c$ is the Schmidt number (i.e., the ratio of the turbulent viscosity to the particle eddy diffusivity) and $C$ is an empirical constant. Most dry deposition parameterizations impose a numerical value to the term C SC that ranges from about 0.6 to 1 (e.g., Slinn \& Slinn, 1980; Zhang et al., 2001). For their part, Zhang and Shao (2014) compute Sc by taking the trajectory-crossing effect (e.g., Yudine, 1959) into consideration and thus only assume a numerical value to $C(0.45)$. These authors also use an expression slightly modified in the case of rough surfaces (the constant $C$ is suppressed, and a characteristic height of the roughness elements is used instead of $z_{0}$ ).

The surface resistance, $r_{\mathrm{s}}$, depends strongly on the properties of the surface that control its capability to trap definitively the particles. The three main processes influencing the surface resistance are Brownian diffusion, interception, and inertial impaction. The first one concerns mainly the submicron particles, whereas the other two are most important for the deposition of particles in the 1- to $10-\mu \mathrm{m}$ size range. The surface resistance is the sum of the inverse of these three components weighted by a rebound function to account for the nonperfect sticking of the particles when they hit the surface.

In dry deposition parameterizations, the efficiency of the collection attributable to Brownian motion is expressed as a more (e.g., Petroff et al., 2008) or less (Zhang et al., 2001) sophisticated expression of Schmidt's number. The particle inertial impaction, that is, the collection of particles on the roughness elements present on a given surface due to the inertia of particles depends on the particle Stokes number, St, and on the obstacle geometrical characteristics:

$$
S t=\frac{\tau_{\mathrm{p} u_{*}}}{A}
$$

where $A$ is the characteristic dimension of the roughness elements and $\tau_{\mathrm{p}}$ is the particle relaxation time: 


$$
\tau_{\mathrm{p}}=\frac{V_{\mathrm{s}}}{g}
$$

The collection of particles by interception occurs when the particle passes an obstacle at a distance shorter than its physical dimensions. In dry deposition parameterizations, various expressions are used to describe interception, but all express their efficiency as being directly proportional to the size of the particle and inversely proportional to that of the roughness elements (e.g., Giorgi, 1986; Slinn, 1982; Zhang et al., 2001; Zhang \& Shao, 2014).

In almost all dry deposition parameterizations, the terms constituting the surface resistance are weighted by a term accounting for the immediate bounce-off of particles upon deposition and their reentrainment by the airflow. Only particles having a sufficient kinetic energy are liable to rebound when they hit the surface, generally those larger than $5 \mu \mathrm{m}$ in diameter. The estimation of the rebound of atmospheric particles over natural surfaces is not a well-resolved question. The most common parameterization used to express the fraction of particles sticking to the surface, $R$, is that derived by Slinn (1982) from an adjustment of the data obtained by Chamberlain $(1966,1967)$ who studied the deposition of Lycopodium spores and other small particles on natural and sticky grass:

$$
R=\exp (-b \sqrt{S t})
$$

Various values of $b$, generally ranging between 0.2 and 2 are found in the literature (e.g., Giorgi, 1986; Slinn, 1982; Zhang et al., 2001; Zhang \& Shao, 2014).

\section{Materials and Methods}

\subsection{Data Acquisition}

The experiment was part of the Special Observing Period 1 of the African Monsoon Multidisciplinary Analysis (AMMA) program and took place close to Banizoumbou $\left(13.54^{\circ} \mathrm{N}, 2.66^{\circ} \mathrm{E}\right.$; altitude: $\left.237 \mathrm{~m}\right)$, a small village located about $60 \mathrm{~km}$ east of Niamey (Niger). The site is a Sahelian remote place mainly devoted to agriculture, that is, a mosaic of cultivated fields and fallows. The agricultural field on which the experiment was set up was one of the largest in the area. The sandy soil was almost bare: At the time of the experiment (mid-June), most of the plant residues from the previous year have been decomposed or grazed. Indeed, as observed by Abdourhamane Touré et al. (2011), the crop residue estimated at the end of the dry season was very low on this field, less than $100 \mathrm{~kg} / \mathrm{ha}$, covering about $1 \%$ of the surface.

The measurement station consisted of two instrumented platforms: a container buried underground and a tower located $3.8 \mathrm{~m}$ north of the container. The two platforms were installed near the center of the field in order to ensure a maximal fetch in the dominant wind directions. The fetch varied between $190 \mathrm{~m}$ in the northeast direction and $575 \mathrm{~m}$ in the south direction.

\subsubsection{Aerosol Measurements}

\subsubsection{Aerosol Sampling}

The design of the station was thought to perform dust flux measurements. Thus, the aerosol sampling flux was performed using two identical inlet systems called IPC (isokinetic particle collector) positioned at 2.1 and $6.5 \mathrm{~m}$ above the soil surface for the container and the tower, respectively. The inlets were designed for the AMMA field campaigns to avoid any size distribution bias due to particle collection.

They consist of a sampling head (56-mm diameter) in which the airflow is kept constant at $50 \mathrm{~m}^{3} / \mathrm{h}$ by a rotating pump controlled by a volume flow controller inserted in the airflow. In order to optimize the collection of large particles, the sampling head is equipped with a wind vane maintaining the opening always faced to the wind. The sampling head is followed by a $110-\mathrm{mm}$ divergent where particles are decelerated and transported into a vertical cylindrical chamber (150-mm diameter, $2.7 \mathrm{~m}$ high) in which seven sampling lines are inserted. These seven sampling lines can be connected to different online instruments or offline collectors. The diameter of each sampling line has been designed to match the nominal flow rate required by the connected instrument. Calculations indicate that particles of aerodynamic diameter of about $40 \mu \mathrm{m}$ are transported with $50 \%$ efficiency at the entrance of the sampling lines. These two sampling heads had 
been carefully intercompared at the beginning of the AMMA campaigns. For details, see Rajot et al. (2008) and Sow et al. (2009).

\subsubsection{Particle Concentration Measurements}

Two tapered element oscillating microbalances (TEOM ${ }^{\oplus}$, model 1400a; Patashnick \& Rupprecht, 1991) were used to measure simultaneously on each platform the total suspended particle mass concentration with a flow rate of $3 \mathrm{~L} / \mathrm{min}$. The sample stream was preheated to $50^{\circ} \mathrm{C}$ before entering the mass transducer so that the measurement was always performed at very low and constant humidity. The selected averaging time for data acquisition was $2 \mathrm{~min}$.

\subsubsection{Particle Size Measurements}

The number size distribution $\left(\mathrm{cm}^{-3}\right)$ was also measured simultaneously on each platform by using two optical particle counters (OPCs; model 1.108, GRIMM ${ }^{\circledR}$ Aerosol Technik GmbH \& Co., Ainring, Germany). These OPCs allowed the measurement of the number concentration in 15 optically equivalent diameter size classes over a large particle size range $(0.3-0.4,0.4-0.5,0.5-0.65,0.65-0.8,0.8-1.0,1.0-1.6,1.6-2.0,2.0-3.0,3.0-4.0$, $4.0-5.0,5.0-7.5,7.5-10,10-15,15-20$, and $>20 \mu \mathrm{m})$. Aerosols were sampled inside the OPCs at a controlled volume flow rate of $1.2 \mathrm{~L} / \mathrm{min}$, and two optical sensors provided near-real-time particle number concentration measurements at a maximum logging rate of $0.17 \mathrm{~Hz}$ (or $6 \mathrm{~s}$ ). Averaging time was $1 \mathrm{~min}$. We derived from the OPC measurements the volume of particles by size classes by assuming that particles are spherical. Because the size distribution is generally well represented by a power or logarithmic function, we used the geometric mean, calculated from the lower and higher limits of each particle size range, as the mean diameter representative of each size class. Because of very low and noisy counts, we do not use the last channel (>20 $\mu \mathrm{m}$ in diameter).

These measurements of the number size distribution were performed with maximum care. Prior to the experiment itself, we cross-calibrated the two OPCs channel by channel by using them to measure the size-resolved concentration of ambient particles at the same height and for a duration of 20 days. In all channels except the coarsest one, an excellent correlation was found for data averaged over 2-min time steps ( $R=0.93$ for the coarsest channel and $R>0.98$ for all the others). The slopes of the regression ranged between 0.87 and 1.13 , depending on the channel. We also intercompared the two OPCs once they were located at their final heights by selecting periods of the day (mainly afternoons) between 1 and 15 June 2006 without dust emission but with enough convection to assume a well-mixed surface layer. The results also presented similar correlation coefficients and slopes of the regressions close to those determined prior to the experiment except for two channels (3-4 and 4-5 $\mu \mathrm{m}$ ) for which the slopes previously found were lower (0.896 and 0.947 instead of 1.037 and 1.128). Thus, the slopes determined in gradient positions were subsequently used to make the concentrations measured at the two levels consistent.

At $2.1 \mathrm{~m}$, a nephelometer (TSI ${ }^{\oplus}$, model 3563) was used to measure with a 2-min temporal resolution and at three wavelengths $(450,550$, and $700 \mathrm{~nm})$ the aerosol scattering coefficients $\left(\sigma_{\text {neph, } \lambda}\right.$ in $\left.\mathrm{m}^{-1}\right)$ integrated between $7^{\circ}$ and $170^{\circ}$. At a given wavelength, these scattering coefficients are extensive quantities that increase with the aerosol concentration and also depend on its particle size distribution and refractive index. Another important aerosol characteristic derived from nephelometer measurements is the spectral dependence of the scattering coefficients. This dependence is an intensive parameter in the sense that it depends on the aerosol-relative size distribution and refractive index but contrary to $\sigma_{\text {neph, } \lambda}$ not on the aerosol concentration. In the visible spectrum, $\sigma_{\text {neph }}$ can be described as a power law of $\lambda$ :

$$
\sigma_{\text {neph }, \lambda}=\alpha \lambda^{-A_{\text {neph }}}
$$

where $\alpha$ is a constant and $A_{\text {neph }}$ is the nondimensional Angström exponent. We compute $A_{\text {neph }}$ from the nephelometer measurements at 450 and $700 \mathrm{~nm}$ :

$$
A_{\text {neph }}=-\log \left(\sigma_{\text {neph }, 450} / \sigma_{\text {neph,700 }}\right) / \log (450 / 700)
$$

Values of $A_{\text {neph }}$ were used to provide a complementary information on the particle size since the Mie theory shows that $A_{\text {neph }}$ increases when the size of the aerosol particles decreases (for details, see Alfaro et al., 2003; Anderson \& Ogren, 1998). 


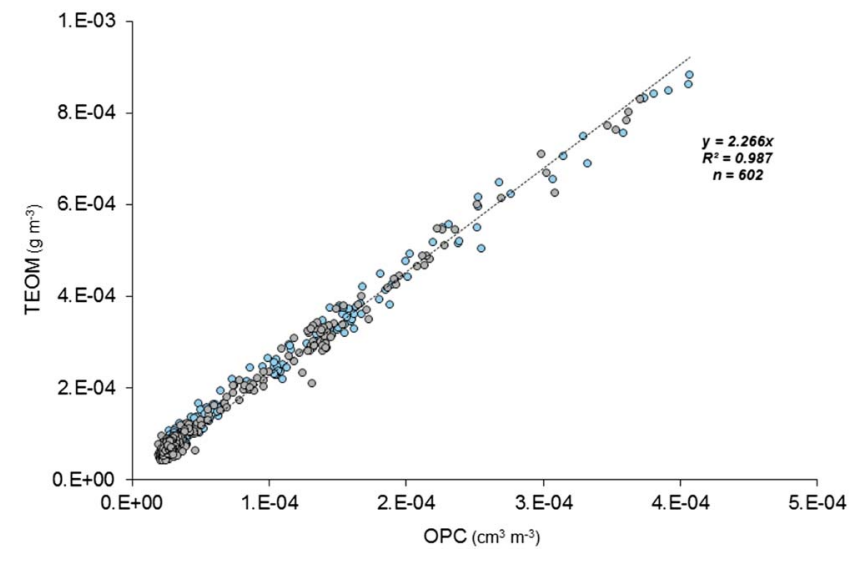

Figure 1. Comparison between the total suspended particulate mass measured by tapered element oscillating microbalance $\left(\mathrm{TEOM}^{\oplus} ; \mathrm{g} / \mathrm{m}^{3}\right.$ ) and the total particulate volume derived from the number size distribution measured by optical particle counter (OPC; $\mathrm{cm}^{3} / \mathrm{m}^{3}$ ) assuming spherical particles. Data are averaged over $2 \mathrm{~min}$ and cover the period 0716-1800 UTC on June 18. Blue circles: measurements at $6.5 \mathrm{~m}$; gray circles: measurements at $2.1 \mathrm{~m}$.

\subsubsection{Consistency of the Aerosol Measurements}

We tested the consistency of the 2-min measurements performed with the $\mathrm{TEOM}^{\circledast}$ and OPC instruments. Figure 1 shows a very good agreement between the volume deduced from the OPC measurements (i.e., the sum of the volumes computed by channel) and the particulate matter concentration as measured by the TEOM ${ }^{\varpi}$ instruments $(R>0.98$ for $n=602)$. The slope of the regression, $a=2.266 \mathrm{~g} / \mathrm{cm}^{3}$, corresponds to the density of the dust particles, a density close to that of the principal minerals (quartz, clays, calcite, feldspars, etc.) constituting mineral dust. The densities derived specifically from the 2.1 and $6.5 \mathrm{~m}$ couples of OPC and TEOM ${ }^{\circledR}$ data are very close $\left(2.264\right.$ and $2.259 \mathrm{~g} / \mathrm{cm}^{3}$, respectively, i.e., $\left.\pm 0.22 \%\right)$. These values of the dust density are also consistent with those obtained by Sow et al. $\left(2009 ; 2.38 \mathrm{~g} / \mathrm{cm}^{3} \pm 0.24\right)$ on the same site, using the same method, but during dust emission events. Note that these densities are "equivalent" mass densities. Indeed, they are derived from (i) volumes based on the assumption that dust particles are spherical while various studies suggest that the aspect ratio for African dust particles is close to 1.5-1.7 (e.g., Chou et al., 2008; Kandler et al., 2007; Klaver et al., 2011) and (ii) on diameters that are optically equivalent particle diameters. In the following, the equivalent mass density of $2.27 \mathrm{~g} / \mathrm{cm}^{3}$ is used to convert number concentrations into mass concentrations.

\subsubsection{Wind Erosion Measurements}

A saltiphone (Eijkelkamp, Giesbeek, The Netherlands) located $5 \mathrm{~m}$ from the isokinetic particle collectors was used for identifying the periods during which saltation occurred. This instrument works according to the acoustic measuring principle (Spaan \& van den Abeeleb, 1991). Saltating grains are counted at $9 \mathrm{~cm}$ above the soil surface, and the digital output signal is cumulated over a 10-s time step and is registered by a data logger.

\subsubsection{Meteorological Measurements and Data Processing}

\subsubsection{Instrumentation}

The wind and temperature profiles were measured from a meteorological mast equipped with a wind vane (W200P Vector Instrument ${ }^{\oplus}$ ), five anemometers (A100R Vector Instrument ${ }^{\oplus}$ ), and four temperature probes (ASPTC, Aspirated Shield With Fine Wire Thermocouple type Chromel Constantan; Campbell ${ }^{\circledR}$ ) positioned above ground level at $0.35,0.8,1.5,2.32,4.7 \mathrm{~m}$ and $0.59,1.28,2.11$, and $4.48 \mathrm{~m}$, respectively. The data were scrutinized every $10 \mathrm{~s}$ and averaged over a 1-min period.

\subsubsection{Data Processing}

As mentioned in section 2, in neutral conditions, the vertical gradient of the wind velocity can be described using equation (4). In nonneutral conditions, correction functions are added to this equation to account for diabatic states:

$$
u_{(z)}=u_{*} / k\left[\ln \frac{z}{z_{0}}-\psi_{\mathrm{m}}\left(\frac{z}{L}\right)+\psi_{\mathrm{m}}\left(\frac{z_{0}}{L}\right)\right]
$$

where $\psi_{\mathrm{m}}$ is the momentum stability function and $L$ is the Monin-Obukhov length (Monin \& Obukhov, 1954), reflecting the thermal stability of the surface boundary layer:

$$
L=\frac{u_{*}^{2}}{k g / T_{0}} T_{*}
$$

where $T_{0}$ is the surface temperature (in $\mathrm{K}$ ) and $T_{*}$ is the scaling temperature (in $\mathrm{K}$ ) that characterizes the production of eddy by buoyancy.

A formulation similar to equation (11) can be written for describing the vertical profile of temperature:

$$
\Delta T=T_{\left(z_{2}\right)}-T_{\left(z_{2}\right)}=T_{*} / k\left[\ln \frac{Z_{2}}{z_{1}}-\psi_{\mathrm{H}}\left(\frac{Z_{2}}{L}\right)+\psi_{\mathrm{H}}\left(\frac{z_{1}}{L}\right)\right]
$$

where $\psi_{\mathrm{H}}$ is the heat stability function. 
Different forms of the stability functions have been derived and used in the literature. Following the reviews of Högström (1988) and Foken (2006), we use the formulations obtained by Paulson (1970), Dyer and Hicks (1970), and Hicks (1976):

For unstable conditions,

$$
\psi_{\mathrm{m}}=2 \ln \left(\frac{1+x}{2}\right)+\ln \left(\frac{1+x^{2}}{2}\right)-2 \operatorname{Arctan}(x)+\frac{\pi}{2}
$$

and

$$
\psi_{\mathrm{H}}=2 \ln \left(\frac{1+y}{2}\right)
$$

with

$$
x=\left(1-15 \frac{Z}{L}\right)^{1 / 4} \text { and } y=\left(1-15 \frac{Z}{L}\right)^{1 / 2}
$$

and for stable conditions (Webb, 1970),

$$
\psi_{\mathrm{m}}=\psi_{\mathrm{H}}=-5 \frac{Z}{L}
$$

Practically, $u_{*}, z_{0}, T_{*}, L$ were computed using the iterative routine optimized by Frangi and Richard (2000) for fitting the above equations to the wind speed and temperature profile measurements. These computations are performed over durations of $20 \mathrm{~min}$ (with a time slipping of $5 \mathrm{~min}$ ) because it has been shown that such a duration is required for integrating the major time scales of turbulence occurring in the surface boundary layer (e.g., Dupont et al., 2018; Wieringa, 1993).

During the deposition event (18 June 2006, 0730-1730 UTC, i.e., local time minus $1 \mathrm{hr}$ ) the surface wind direction was south-southwest $\left(205^{\circ} \pm 30^{\circ}\right)$. This allow the fetch to be equal to 88 times the height of the higher particle sampler (i.e., $575 \mathrm{~m} / 6.5 \mathrm{~m}$ ). The aerodynamic roughness length of the surface is very low and allows satisfying easily the limiting value ${ }^{z} / z_{0} \geq 100$ above which the profiles are valid (the height of lower anemometer being $0.35 \mathrm{~m}$ ).

The fitting procedure is applied only when the wind speed is larger than $1 \mathrm{~m} / \mathrm{s}$. Furthermore, following Marticorena et al. (2006), the quality of the inversion procedure is considered as satisfying only when the difference between the computed and measured profiles is less than $5 \%$ for wind speed and less than $0.05 \mathrm{~K}$ for temperature. The results of this inversion allow the computation of additional parameters useful for describing the stability conditions, that is,

-the gradient Richardson number, $R i$ :

$$
\begin{gathered}
R i_{z_{m}}={ }^{z_{m}} / L \text { for } R i_{z_{m}}<0 \text { and } z_{m} / L=\frac{R i_{z_{m}}}{1-5 R i_{z_{m}}} \text { for } 0 \leq R i_{z_{m}}<0.2 \\
\text { with } z_{m}=\left(z_{\min } \cdot z_{\max }\right)^{0.5}
\end{gathered}
$$

$$
\text { -the sensible heat flux, } H_{\mathrm{s}}\left(\mathrm{W} / \mathrm{m}^{2}\right), \quad H_{\mathrm{s}}=-T_{*} u_{*} \rho_{a} C_{p}
$$

where $C_{p}$ is the air isobaric heat capacity $\left(\mathrm{J} \cdot \mathrm{kg}^{-1} \cdot \mathrm{K}^{-1}\right)$.

\subsubsection{Air Mass Trajectories}

Forward air mass trajectories were computed using the National Oceanic and Atmospheric Administration (NOAA) HYbrid Single-Particle Lagrangian Integrated Trajectory (HYSPLIT) model (Rolph et al., 2017; Stein et al., 2015). We selected the matrix option that allows running a grid of trajectories evenly spaced around a point source. We also used the HYSPLIT dispersion model to trace the dust plume. Both models used the $1^{\circ} \times 1^{\circ}$ latitude-longitude grid, National Centers for Environmental Prediction's Global Data Assimilation System wind field reanalysis. 


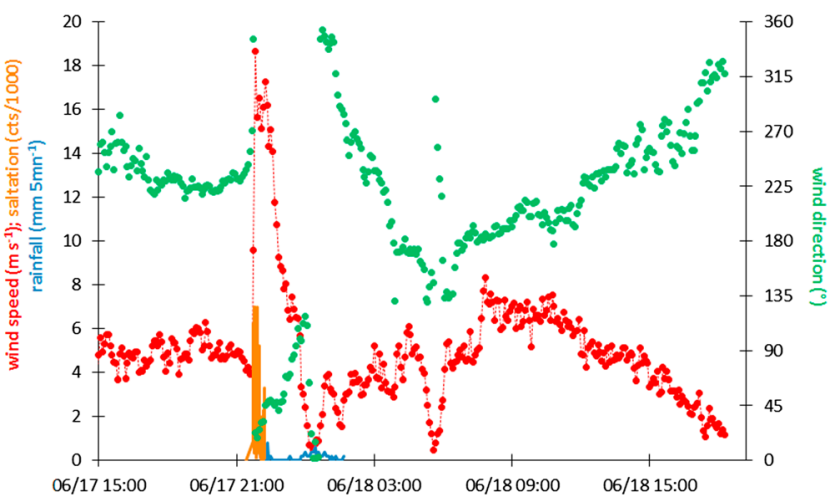

Figure 2. Surface wind speed (red points) and wind direction (green points) at 6.5-m height, saltation counts (orange bars) and precipitation (blue line) as recorded during the mesoscale convective event that occurred in Banizoumbou (Niger) on 17 June 2006.

\section{The 17 June 2006 Dust Emission Event and Its Subsequent Deposition}

\subsection{Meteorological Situation}

In the Sahel, most of the wind erosion events occur from May to mid-July when the protection of the soil surface by vegetation and crop residues is the lowest and episodes of high wind velocities the most frequent (e.g., Abdourhamane Touré et al., 2011; Bergametti et al., 2017; Bielders et al., 2004; Rajot, 2001). At that time, in West Africa, most of the humidity comes from the South Tropical Atlantic Ocean and is transported northward by the African monsoon. This input of water vapor allows the formation of convective systems of various sizes. When sufficiently developed and well organized, these convective systems are called mesoscale convective system. Most of them have sizes ranging from tens to hundreds of kilometers (Laing \& Fristch, 1993; Marsham et al., 2008; Roberts \& Knippertz, 2012), generate gust fronts induced by convective cold pools, and are generally associated with precipitation.

During the experiment, such a convective mesoscale event affected the Banizoumbou region on 17 June 2006 at 2145 UTC. A sudden change in wind direction (from southwest to north-northeast) was observed when the mesoscale convective system arrived. At the same time, the wind speed rapidly increased to $20 \mathrm{~m} / \mathrm{s}$ (Figure 2) and the saltiphone immediately started recording a huge saltation event. The saltation stopped completely about $30 \mathrm{~min}$ after the precipitation had started although the wind speed remained quite high $(>10 \mathrm{~m} / \mathrm{s}$ ) until 2245 UTC. Then, the wind speed decreased progressively and the wind direction shifted gradually back to its original south-southwest direction. Significant precipitation

NOAA HYSPLIT MODEL Forward trajectories starting at 2300 UTC 17 Jun 06 GDAS Meteorological Data

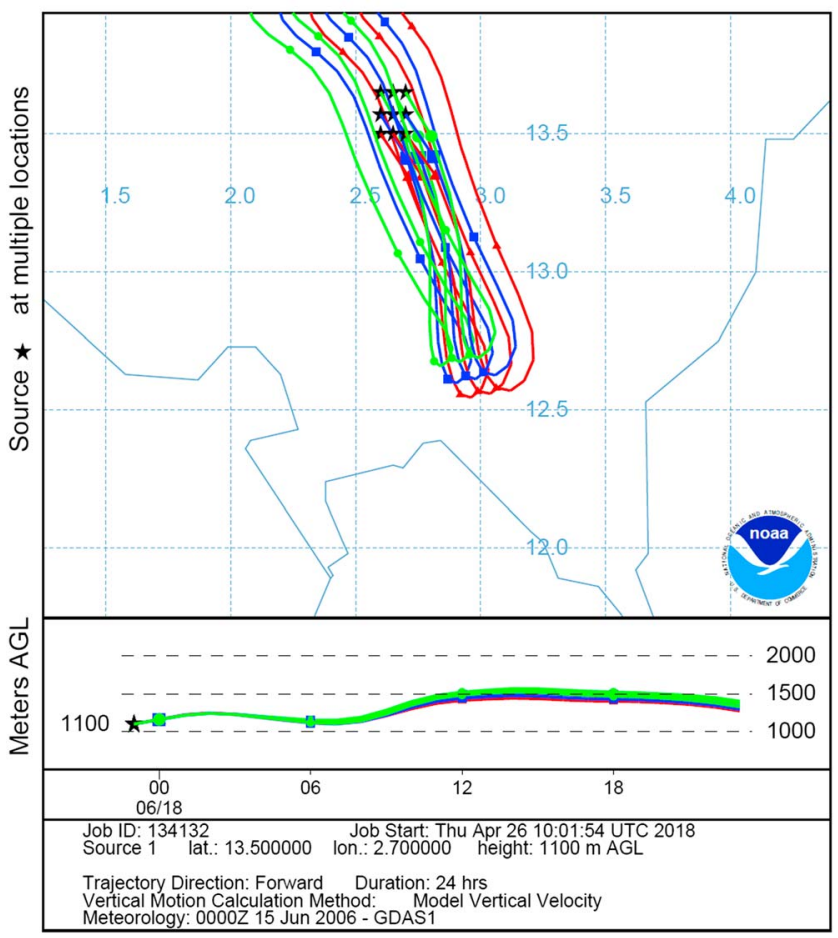

Figure 3. Eighteen-hour forward trajectories starting on 17 June 20062300 UTC from an area ranging from $13.5^{\circ} \mathrm{N}-13.65^{\circ} \mathrm{N}$ and $2.6^{\circ} \mathrm{E}-2.7^{\circ} \mathrm{E}$ (black stars). NOAA = National Oceanic and Atmospheric Administration; HYSPLIT = HYbrid Single-Particle Lagrangian Integrated Trajectory; GDAS = Global Data Assimilation System; AGL = above ground level. (about $7 \mathrm{~mm}$ ) occurred mainly between 17 June 2150 UTC and 18 June 0140 UTC.

On 18 June, the surface wind speed was rather low $(<5 \mathrm{~m} / \mathrm{s})$ in the early morning but increased progressively to reach about 7-8 $\mathrm{m} / \mathrm{s}$ between 0800 and 1030 UTC. This increase of the wind speed in the morning is a well-established pattern in this region and is associated with an increase of turbulence by surface heating, allowing downward mixing of momentum from the nocturnal low-level jet (e.g., Lothon et al., 2008). However, no saltation was observed at that time, probably because the soil was moist (e.g., Bergametti et al., 2016). Then, when the wind direction turned again to north-northwest ( $\approx 1300$ UTC), the wind speed decreased progressively to reach $2 \mathrm{~m} / \mathrm{s}$ in the late afternoon. On 18 June, the sky remained cloudy as can be seen on the Moderate Resolution Imaging Spectroradiometer Terra and Aqua images taken respectively at 0950 and 1255 UTC (not shown).

As mentioned above, the wind direction reversed during the night and this allowed the air mass loaded with dust particles to pass again over the Banizoumbou site during daytime on 18 June. The forward trajectories starting from the Banizoumbou region on 17 June at 2300 UTC confirm that the air mass loaded with dust during the erosion event came back to the site on 18 June (Figure 3). The dispersion model clearly illustrates first the southeastward transport of the dust plume and then its turning back to the northwest in the early morning (see Movie S1 in the supporting information).

\subsection{Particle Concentrations and Gradient}

To protect the aerosol instruments (TEOM ${ }^{\varpi}$ and OPC), the sampling was stopped just after the beginning of the rain. When the rain stopped, the 


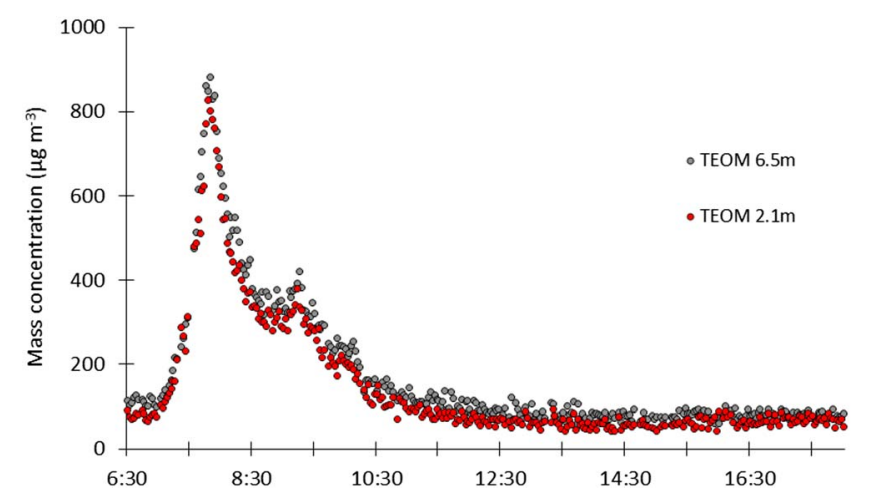

Figure 4. Evolution of the particulate matter mass concentrations measured by the tapered element oscillating microbalance $\left(\mathrm{TEOM}^{\oplus}\right)$ instruments on 18 June 2006. aerosol inlets and the aerosol instruments were cleaned and turned on again at 0630 UTC (TEOM $^{\circledR}$ ) and 0715 UTC (OPC) on 18 June, that is, just in time to record the arrival of the dust plume on the site. At about 0700 UTC, the TEOM ${ }^{\circledast}$ instruments registered an abrupt change in the particulate matter concentration that increased from about $120 \mu \mathrm{g} / \mathrm{m}^{3}$ to more than $880 \mu \mathrm{g} / \mathrm{m}^{3}$ in less than $1 \mathrm{hr}$ (Figure 4). Then, the particle mass concentration progressively decreased until 1230 UTC to stabilize at around $80-100 \mu \mathrm{g} / \mathrm{m}^{3}$.

The negative difference of concentration between the TEOM $^{\circledR}$ instrument measuring at $2.1 \mathrm{~m}$ and that measuring at $6.5 \mathrm{~m}$ clearly shows that this dust episode corresponded to a huge deposition event. The whole day long, the particulate matter concentration remained significantly larger at $6.5 \mathrm{~m}$ than at $2.1 \mathrm{~m}$. The difference was as high as 60 to $100 \mu \mathrm{g} / \mathrm{m}^{3}$ at the beginning of the event and remained higher than $15 \mu \mathrm{g} / \mathrm{m}^{3}$ during most of the day (Figure 5).

\subsection{Particle Size Distribution}

The changes in particle concentrations are concomitant with the changes in the particle size distribution. The fact that the Angström coefficient measured by the nephelometer suddenly became very low and even negative $(\approx-0.4)$ around 0700 UTC clearly indicated the arrival of a dust air mass characterized by the presence of coarse particles (Figure 6). Afterward, this coefficient increased slowly until midday to reach about 0.15 , a value slightly positive but still indicative of the presence of large particles although finer than those carried by the air masses in the early morning.

The OPC measurements allow describing more quantitatively this evolution of the particle size distribution (Figure 7). Particles having a diameter between 3 and $10 \mu \mathrm{m}$ dominate (>90\%) the particle mass size distribution from 0730 to 1130 UTC. After that and until 1730 UTC, in agreement with the evolution of the Angström coefficient, the abundances of the largest particle size classes decrease slowly and the mass size distribution is dominated by the particles in the 1.5 - to $5-\mu \mathrm{m}$ particle size range. The contribution of the submicron particles to the mass size distribution is very low in the early morning $(<3 \%)$ but progressively increases without exceeding 13\%. The presence of a significant amount of large particles indicates that the dust cloud reaching the site in the early morning is not very aged. When the day progresses, the dusty air masses arriving on the site are more aged and a significant part of their coarsest particles has been probably lost on the way.

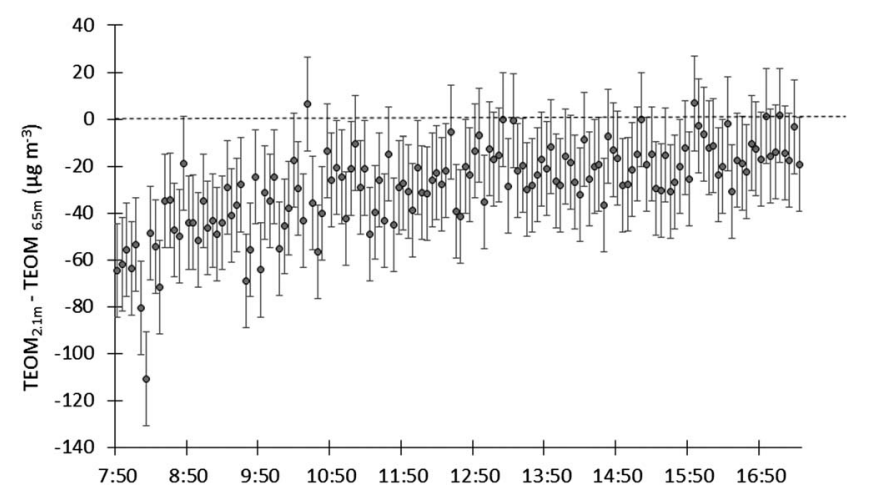

Figure 5. Differences between the 20-min averaged particulate matter concentrations (with a slipping time step of $4 \mathrm{~min}$ ) measured by the tapered element oscillating microbalance $\left(\mathrm{TEOM}^{\circledR}\right)$ instruments at two different heights (2.1 and $6.5 \mathrm{~m}$ ) on 18 June 2006.

\section{Results}

\subsection{Meteorological Conditions During Dust Deposition 5.1.1. Stability Conditions}

The wind friction velocity, $u_{*}$, and the temperature scale, $T_{*}$, can be used to trace the origin (dynamical and/or thermal) of the turbulence controlling the atmospheric stability. Their time evolution on 18 June and that of the sensible heat flux, $H_{s}$, are reported in Figure 8.

The wind friction velocity slowly increases from 0600 to 0800 UTC, stabilizes around $0.3-0.4 \mathrm{~m} / \mathrm{s}$ until midday and then decreases to reach $0.2 \mathrm{~m} / \mathrm{s}$ at the end of the afternoon. As mentioned before, the higher values of the wind friction velocity in the morning likely result from the strengthening of the surface wind speed in the early morning due to the downward mixing of momentum from the nocturnal low-level jet. However, on 18 June, this enhancement of the surface wind speed is moderate (less than $8 \mathrm{~m} / \mathrm{s}$; see Figure 2). Indeed, at that time, the sensible heat flux is close to zero, and this does not favor vertical mixing.

In fact, the sensible heat flux exhibits a nonclassical diurnal pattern: It remains very low (maximum $60 \mathrm{~W} / \mathrm{m}^{2}$ ) during all along the 18 June 2006 


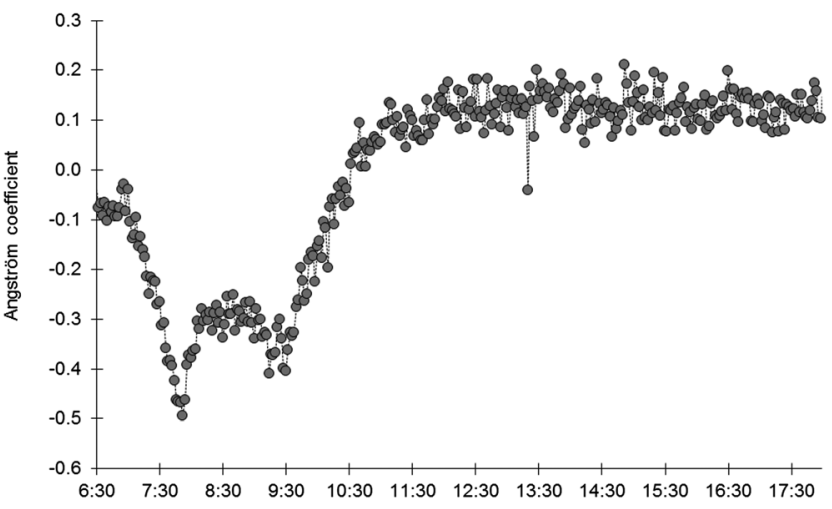

Figure 6. Evolution of the Angström coefficient ( $450 / 700 \mathrm{~nm}$ ) during 18 June 2006. with a long stagnation period (0600-1100 UTC) corresponding roughly to the period during which the dust concentration was the largest. Figure 9 shows that the diurnal cycle of the temperature is different on 18 June than it was on the previous or following days. In particular, a sudden and abrupt decrease in temperature $\left(\sim-13^{\circ} \mathrm{C}\right.$ in less than $\left.1 \mathrm{hr}\right)$ occurred on 17 June 2200 UTC, that is, when the mesoscale convective event reached the Banizoumbou experimental site and rain started. Moreover, as mentioned before, the sky remained cloudy on June 18 and the atmosphere very dusty, thus strongly limiting the incoming solar flux at the surface. Thus, the surface temperature was not able to reach as high values as those observed during the morning and early afternoon on the previous or following days.

Figure 10, directly inspired from Affre et al. (2000), summarizes these observations and provides an overall view of the stability conditions encountered during 18 June. Five-minute periods are classified according to the scales of speed $\left(u_{*}\right)$ and temperature $\left(T_{*}\right)$. In this figure, a network of hyperbolae represents the isovalues of sensible heat flux, whereas the isovalues of the stability parameter ${ }^{1} / L$ correspond to a network of parabola. The isolines corresponding to low absolute values of $1 / \mathrm{L}$ are located close to $T_{*}=0$ corresponding to neutrality. Stability or instability increase with absolute values of $1 / L$ and larger values are observed close to the $x$-axis. Taking into account that our experimental field had a very smooth sandy surface, values of $1 / L$ ranging from -0.02 to 0.01 can be considered as indicative of neutral or quasi-neutral stability conditions (e.g., Golder, 1972).

From the arrival of the dust cloud (0700 UTC) to about 1215 UTC, most of the consecutive 5-min periods were in neutral or quasi-neutral conditions. Afterward, the conditions were slightly unstable with $1 / \mathrm{L}$ ranging from -0.02 to -0.05 and $H_{\mathrm{s}}$ was maximum $\left(\sim 50-60 \mathrm{~W} / \mathrm{m}^{2}\right)$, but $u_{*}$ remained sufficiently high $(\sim 25-30 \mathrm{~cm} / \mathrm{s})$ to produce the dynamical turbulence necessary to counterbalance the low production of thermal turbulence.

Most of the time, dry deposition occurred during neutral or almost neutral stability conditions. Thus, the number of rejected 5-min periods (i.e., periods not satisfying the conditions described in 3.1.3) is null and the stability corrections we had to apply were very limited for the whole day, giving good confidence in the retrieved dynamical parameters.

\subsubsection{Roughness Length}

The aerodynamic roughness length, $z_{0}$, is an important parameter that characterizes the capability of the surface to trap the wind momentum. Even if it can only be precisely determined from wind velocity measurements, $z_{0}$ is linked to the density and height of the roughness elements present on the surface (e.g., Lettau, 1969; Marticorena et al., 1997, 2006).

Because $z_{0}$ is much more sensitive to doubts and stability corrections, we restricted its determination to the period during which the stability conditions can be considered as neutral or quasi-neutral $(-0.02$ $<1 / L<0.01$ ). These conditions were observed between 0647 UTC and 1217 UTC, the period during which $z_{0}=0.00076 \pm 0.00044 \mathrm{~m}(n=75)$. This value of the aerodynamic roughness length is typical of the roughness lengths measured in situ or in wind tunnel for bare or almost bare sandy surfaces (e.g., Greeley et al., 1991, 1997; Lancaster, 2004; Marticorena et al., 2006; Xian et al., 2002; Zhang et al., 2014).

\subsection{Dust Dry Deposition}

\subsubsection{Gradient Method for Dust Particle Fluxes}

Inside the boundary layer, one can define an atmospheric layer close to the surface where the fluxes vary by less than $10 \%$ of their magnitude with height (e.g., Rossby \& Montgomery, 1935; Stull, 1988). This surface layer is thus assumed to be a constant flux layer under the assumptions of steady state and horizontal homogeneity. In this layer, the vertical flux of particles, $F$,can be separated into two contributions: one linked to the action of gravity on particles, the other resulting from the action of the turbulent and molecular diffusion. This latter flux is connected to the average concentration gradient via the turbulent diffusivity coefficient. The constant vertical flux is then as follows: 

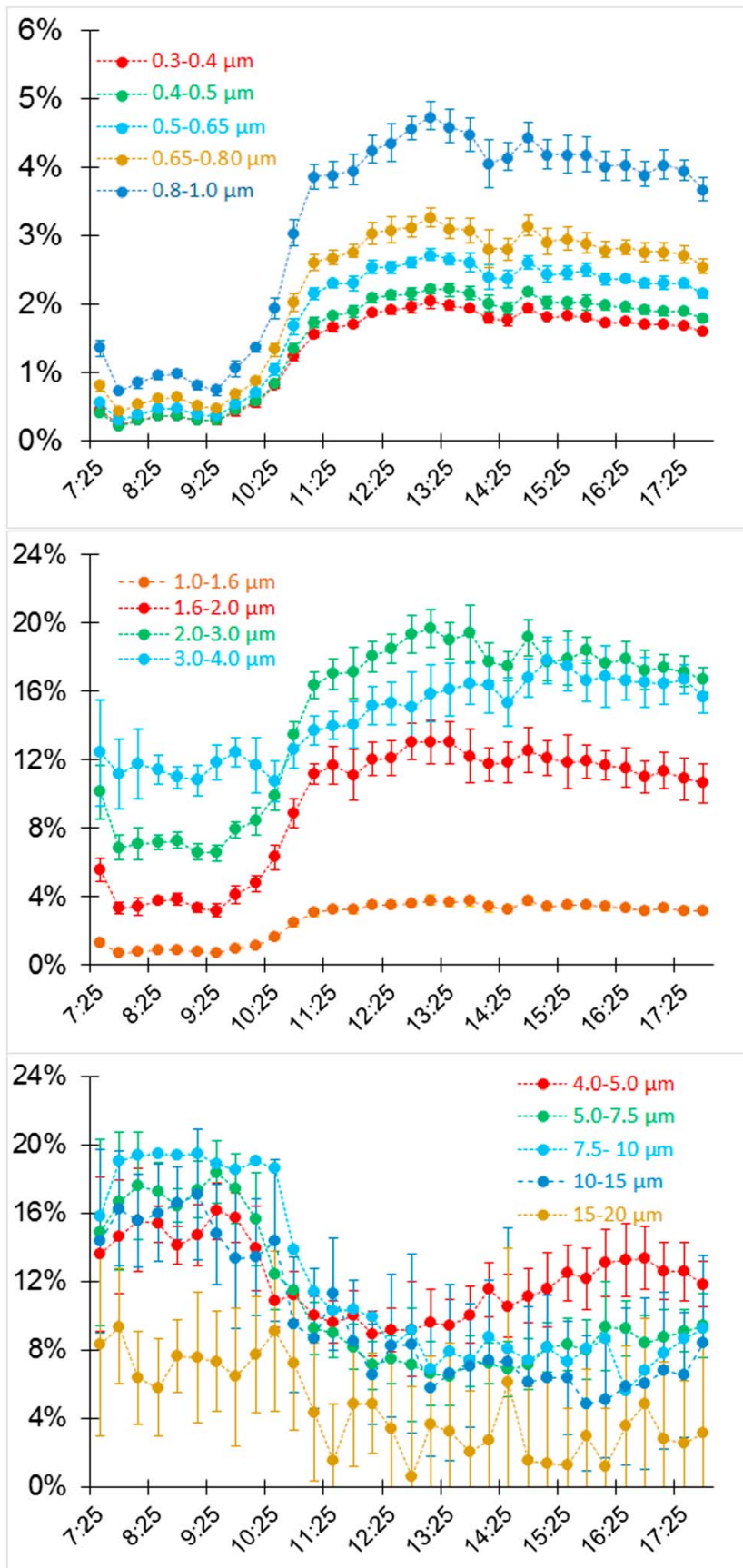

Figure 7. Temporal evolution of the mass size distributions of particles for the various size classes of the optical particle counter at $2.1 \mathrm{~m}$ for 18 June 2006. The data are averaged over 20 -min periods, and the vertical bars represent the standard deviation of the data for each 20-min period.

$$
F=-K_{p} \frac{\partial C}{\partial z}-V_{\mathrm{S}} C
$$

where $K_{p}$ is the eddy diffusivity or turbulent transfer coefficient (in $\mathrm{m}^{2} / \mathrm{s}$ ) of the particles, $\frac{\partial C}{\partial z}$ is the particles concentration gradient (in $\mathrm{kg} \cdot \mathrm{m}^{-3} \cdot \mathrm{m}^{-1}$ ) in the vertical direction $z$, and $V_{\mathrm{s}}$ is the gravitational settling velocity as expressed by equation (1). By convention, a downward flux (i.e., deposition) is negative.

As shown by equation (1), the gravitational settling is independent of the concentration gradient, and thus, the measurement of the vertical concentration gradient only yields the diffusive deposition flux, $F_{\text {diff: }}$

$$
F_{\text {diff }}=-K_{p} \frac{\partial C}{\partial z}
$$

For applying equation (22), it is necessary to assume a similarity between the eddy diffusivity of particles and those of momentum or heat. The relationship between these quantities is well described far from the roughness of the surface, which is to say at an altitude greater than about 100 times the aerodynamic roughness length, $z_{0}$ (e.g., Businger, 1986). However, this similarity depends on the particle size, large particles having a greater inertia and being more affected by the gravity force. Thus, they are more prone to follow trajectories different from those of the air parcels. After analyzing various models accounting for this trajectory-crossing effect, Shao (2008) concluded that the eddy diffusivities of particles smaller than $20 \mu \mathrm{m}$ in diameter and of scalars can reasonably be considered identical when turbulence is sufficiently strong.

Equation (22) can be integrated between two measurement heights $z_{1}$ and $z_{2}\left(z_{2}>z_{1}\right)$ :

$$
F_{\text {diff }}=-\frac{u_{*} \Delta z k}{\ln \left(z_{2} / z_{1}\right)-\Psi_{\mathrm{m}_{, z 2}}+\Psi_{\mathrm{m}_{\mathrm{z} 1}}} \frac{\Delta C}{\Delta z}
$$

where $\Delta C$ (in $\mathrm{kg} / \mathrm{m}^{3}$ ) is the concentration difference between the heights $z_{2}$ and $z_{1}$ and $\Psi_{\mathrm{m}_{z i}}$ is the stability correction for momentum transfer at each height.

Shao (2008) pointed out that if the dust flux, $F$, is constant with height, the diffusive dust flux, $F_{\text {diff, }}$ is not because of the gravitational settling term. Thus, the diffusive dry deposition velocity, $V_{\text {diff, }}$ at a height, $z$, is

$$
V_{\text {diff }}(z)=-\frac{F_{\text {diff }}(z)}{C(z)}
$$

\section{$V_{\text {diff }}(z)$ being downward positive.}

The large difference (Figure 5) observed between the particle concentrations measured at 2.1 and $6.5 \mathrm{~m}$ allows using equations (23) and (24) to compute the diffusive dust deposition fluxes and the diffusive dry deposition velocities, respectively. Because the evolution of the vertical profiles with height are generally close to logarithmic, the geometric height is commonly used as the height characterizing the profile, that is, the height where the tangent to the profile is equal to the gradient (Businger, 1986). In our case, the geometric height, $z$, is equal to $3.69 \mathrm{~m}$.

Practically, the diffusive deposition fluxes derived from the bulk concentration measurements are directly computed from the difference in particle concentrations measured by the two TEOM ${ }^{\circledast}$ instruments. In perfect timing with the computation of both $u_{*}$ and the stability functions, this computation is performed over 


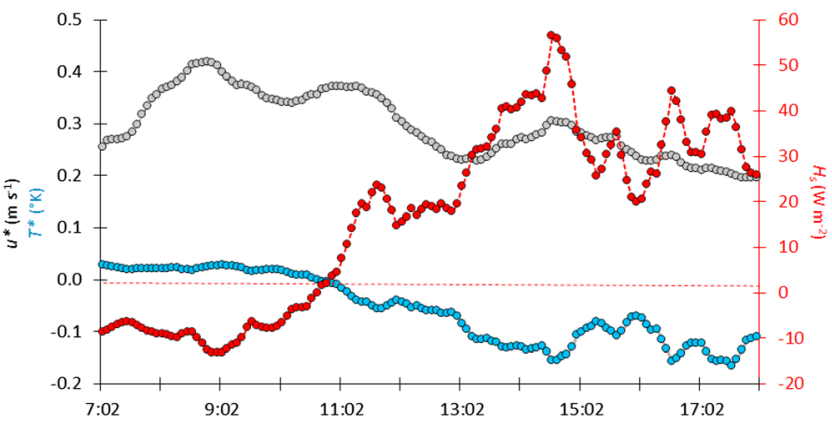

Figure 8. Temporal evolution of the wind friction velocity $(\mathrm{m} / \mathrm{s})$, the temperature scale $(\mathrm{K})$, and the sensible heat flux $\left(\mathrm{W} / \mathrm{m}^{2}\right)$ on 18 June 2006.

20-min periods and with a slipping time step of $5 \mathrm{~min}$. The diffusive vertical fluxes derived from the OPC measurements are computed for each size class and then summed to obtain the total diffusive deposition fluxes. The computations are performed for the same 20-min periods as those used for the computation of the diffusive deposition fluxes from the bulk concentration measurements.

\subsubsection{Dust Deposition Fluxes}

The diffusive dust deposition flux $\left(F_{\text {diff }}\right)$ deduced from the TEOM ${ }^{\circledast}$ and OPC measurements is reported in Figure 11 for the period 0732-1747 UTC. The time evolution of the deposition flux follows that of the dust concentration: The maximum of the deposition is observed around 0800 UTC, that is, when the dust concentration reaches its maximum and the progressive decrease of the $F_{\text {diff }}$ is very similar to the decrease of the dust concentration all along the day. The TEOM ${ }^{\oplus}$ and OPC measurements describe a similar deposition pattern, but the maximum deposition flux derived from the TEOM ${ }^{\circledast}$ measurements is slightly lower than the one derived from the OPC measurements (10.8 and $14.6 \mu \mathrm{g} \cdot \mathrm{m}^{-2} \cdot \mathrm{s}^{-1}$, respectively).

The contribution of the different size classes to $F_{\text {diff }}$ for different time periods of 18 June are computed from OPC size-resolved data (Figure 12). When the deposition is the highest (0737-0827 UTC), 70\% of $F_{\text {diff }}$ is controlled by the particles in the medium size range $(3-7.5 \mu \mathrm{m})$ when these particles account for only about $45 \%$ of the mass size distribution at that time (Figure 6). Surprisingly, the contribution of larger particles (7.5$20 \mu \mathrm{m})$ to deposition is, at that time, less $(\sim 28 \%)$ than their relative contribution to the mass size distribution ( 41\%) and their supposedly higher deposition velocity might suggest. At midday (i.e., 1042-1142 and 12471347 UTC), the largest particles largely dominate the deposition with a contribution to the total deposition exceeding $70 \%$ when the medium size range particles contribute only $\sim 15 \%$ to the total flux. This is also surprising because for this period the contribution of the largest particles to the mass size distribution is about 2 times smaller than it was during the morning (0737-0827 UTC) period. At the end of the afternoon (16371737 UTC), the contribution of the different size classes to the deposition is more homogeneous, with a rebalancing of the contributions of the large, medium, and small particles in phase with the evolution of the mass size distribution observed at that time (Figure 6).

This comparison of the temporal patterns of the diffusive dry deposition fluxes and mass size distributions clearly confirms that particle size is not the only driver of the dry deposition flux. Other factors such as wind friction velocity also play a significant role in deposition processes as shown by many authors from in situ or wind tunnel measurements (e.g., Lamaud et al., 1994; Zhang \& Shao, 2014) and during model intercomparisons (e.g., Kahn \& Perlinger, 2017).

\subsubsection{Dry Deposition Velocities}

Figure 13 reports the diffusive dry deposition velocities derived from the $\mathrm{TEOM}^{\circledR}$ and $\mathrm{OPC}$ measurements. These diffusive dry deposition velocities were computed by dividing $F_{\text {diff }}$ by the geometric mean of the particle concentrations between 2.1 and $6.5 \mathrm{~m}$ for each 20-min averaging period.

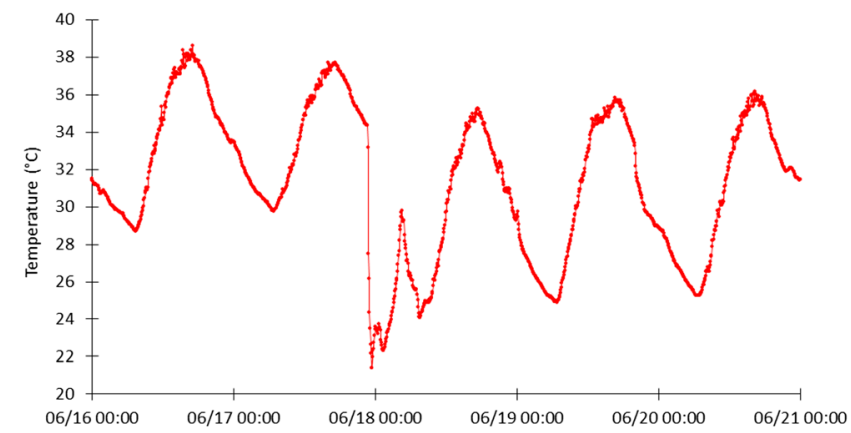

Figure 9. Time series of temperature at $6.5 \mathrm{~m}$ at Banizoumbou (Niger) for the 15-21 June 2006 period. The abrupt change in temperature that occurred on 17 June 2200 UTC is due to the arrival of the mesoscale convective system also responsible for the dust emission.
The time evolutions of the dry deposition velocities and of the dry deposition fluxes are very different: The maximum in $V_{\text {diff }}(\sim 4.5 \mathrm{~cm} / \mathrm{s})$ is not observed when the dry deposition fluxes are the highest but around midday, consistently with the dominant contribution of the large particles to the deposition fluxes at that time. At the maximum of deposition ( 0800 UTC), $V_{\text {diff }}$ is only $1.9 \mathrm{~cm} / \mathrm{s}$.

The temporal evolution of $V_{\text {diff }}$ during 18 June is very different for the 3- to $5-\mu \mathrm{m}$ and 7.5 - to $15-\mu \mathrm{m}$ particle size classes (Figure 14). The diffusive dry deposition velocity for 3 - to $5-\mu \mathrm{m}$ particles roughly follows the general trend of the friction velocity with a maximum around 0800 UTC and then a more or less continuous decrease, but the evolution of $V_{\text {diff }}$ for larger particles only matches that of the wind friction velocity after approximatively 1045 UTC. Indeed, between 0727 and 1030 UTC the diffusive dry 


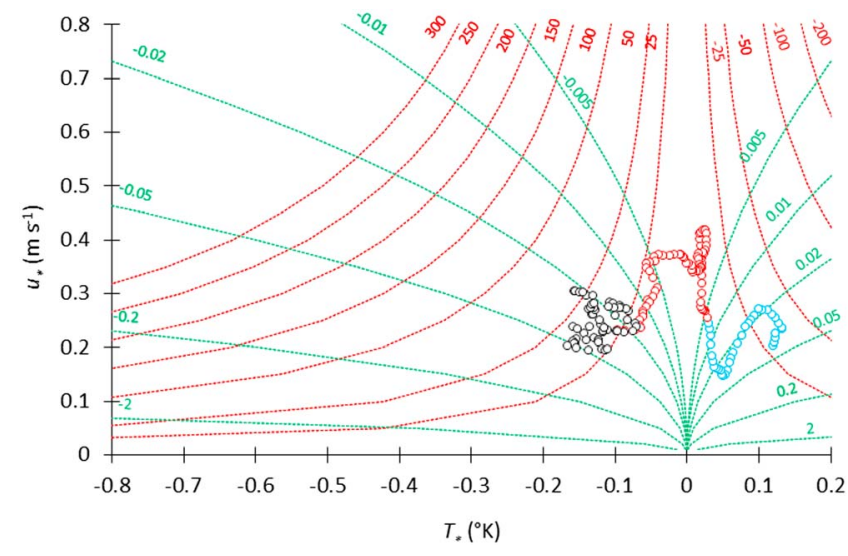

Figure 10. Localization of consecutive 5-min periods for 18 June 2006 in a diagram $u_{*}=f\left(T_{*}\right)$. Blue circles: 0402 to 0657 UTC; red circles: 0702 to 1307 UTC; black circles: 1312 to 1757 UTC. The green lines correspond to isolines of $1 / L\left(\mathrm{~m}^{-1}\right)$ and red ones to isolines of the sensible heat flux, $H_{\mathrm{s}}\left(\mathrm{W} / \mathrm{m}^{2}\right)$.

deposition velocity of the 7.5 - to $15-\mu \mathrm{m}$ particles is very low $(\sim 2.1 \mathrm{~cm} / \mathrm{s})$ and even lower than that of particles in the 3- to $5-\mu \mathrm{m}$ particle size range at the same time $(\sim 3.4 \mathrm{~cm} / \mathrm{s})$. The maximum values of $V_{\text {diff }}$ for the 7 - to $15-\mu$ m particles $(\sim 10-12 \mathrm{~cm} / \mathrm{s})$ are observed between 1042 and 1157 UTC, that is, not when the wind friction velocity is maximum.

\subsubsection{Rebound of Large Particles}

For a given size class, the main driver of the dry deposition velocity is the wind friction velocity: An increase in $u_{*}$ leads to an increase of the surface processes (inertial impaction, interception, and Brownian diffusion) governing the diffusive dry deposition of particles and thus to an increase of the dry deposition velocity. Figure 15 shows that the diffusive dry deposition velocities of fine- and medium-size particles, that is, those $<7.5 \mu \mathrm{m}$ in diameter, are well correlated with $u_{*}$ : For a given size class higher dry deposition velocities are observed for higher wind friction velocities. But Figure 15 also shows that particles $>7.5 \mu \mathrm{m}$ in diameter have not the same behavior: If a relative good covariation of $V_{\text {diff }}$ and $u_{*}$ is observed until the wind friction velocity reaches about $0.3 \mathrm{~m} / \mathrm{s}$, the diffusive dry deposition velocity of these large particles drops sharply for higher $u_{*}$ values.

The only process for which the wind friction velocity has a size-selective negative effect on $V_{d}$ is rebound, that is, the immediate bounce-off of particles upon deposition and their reentrainment by the airflow. Indeed, various authors (e.g., Paw U, 1983; Paw U \& Braaten, 1992; Wu et al., 1992a) have shown that a minimum velocity exists, called the critical rebound velocity, for an impinging particle of a given size for which rebound occurs: Only particles having a sufficient kinetic energy are liable to rebound when they hit the surface. Since the kinetic energy is proportional to the mass of the particle and to the square of its velocity, the particles having a large diameter and moving inside a relatively high velocity airflow are the most affected by this process. When the critical rebound velocity is exceeded, the fraction of particles able to rebound increases rapidly as the particle velocity increases.

Generally, only particles greater than $5 \mu \mathrm{m}$ in diameter have the capability to reach a sufficient kinetic energy to rebound immediately after hitting the surface (e.g., Zhang et al., 2001) and the percentage of rebounding particles could be as high $80 \%$ for $10-\mu \mathrm{m}$ particles for wind friction velocity of the order of $0.3 \mathrm{~m} / \mathrm{s}$ (e.g., Figgis et al., 2018; Wu et al., 1992b). Therefore, in a counterintuitive way, when wind speed is sufficiently strong, higher diffusive deposition velocities can be expected for medium-size particles than for larger particles. Indeed, the medium-size particles have sufficient inertia to extract themselves from eddies but insufficient energy to overcome the adhesion forces tying them to the surface when they hit it. This is what one can observe in Figure 14.

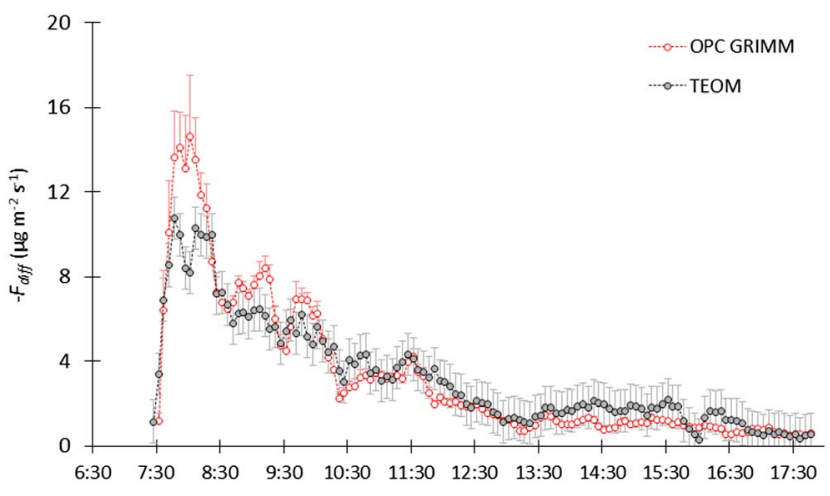

Figure 11. Time evolution of the diffusive dry deposition flux of dust on 18 June 2006. The vertical bars correspond to the standard deviation of $\left(C_{6.5 \mathrm{~m}}-C_{2.1 \mathrm{~m}}\right)$ over the 20-min averaging period. Gray circles: tapered element oscillating microbalance $\left(\right.$ TEOM $\left.^{\circledR}\right)$; red circles: optical particle counter (OPC).
Thus, it is highly probable that differences in rebound efficiency explain the observed patterns of the diffusive dry deposition velocities of the different size classes during early morning on 18 June 2006. Indeed, fineand medium-size particles are not or only little affected by rebound because of their low mass, whereas large particles are, and particularly in the early morning when the friction velocity is the highest. Then, around 1000 UTC, $u_{*}$ decreases and becomes probably lower than the critical rebound velocity, the rebound becomes minimal and the dry deposition velocity of the large particles comes back to a temporal pattern similar to that of the fine- and medium-size particles, that is, a covariation with $u_{*}$ (Figure 14).

As mentioned in section 2, the estimation of the fraction of rebound of atmospheric dust particles over natural surfaces is not a well-resolved question. Despite Slinn (1982) mentioning that the formulation he proposed to account for rebound (equation (8)) is not satisfying, most of the dry deposition schemes developed during the last 30 years (Giorgi, 1986; Zhang et al., 2001; Zhang \& Shao, 2014, among others) used equation (8) 


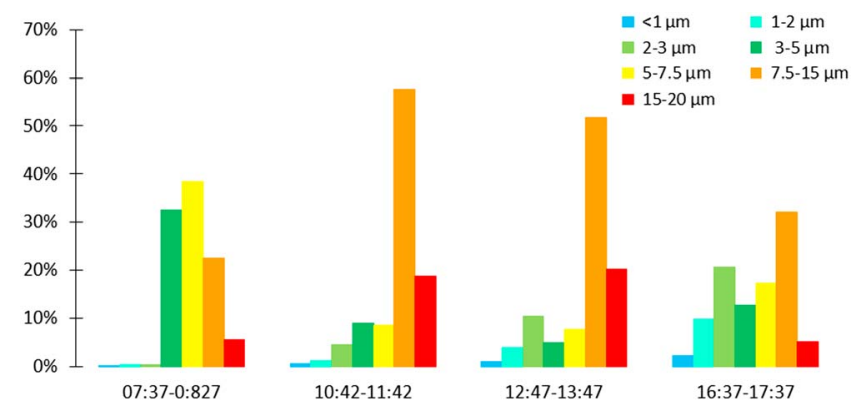

Figure 12. Contribution (\%) of different particle size classes to the dust deposition fluxes measured at different time periods on 18 June 2006.

with only changes in the value attributed to the parameter $b$ (generally taken as 1 or 2 ).

A rough estimate of the rebound can be attempted using the $\mathrm{TEOM}^{\oplus}$ data that are less scattered than those of the individual channels of the OPC are. Figure 16 a shows that the trend between $V_{\text {diff }}$ derived from $\mathrm{TEOM}^{\circledast}$ data and $u_{*}$ is very similar to those observed for the 7.5 - to $10-\mu \mathrm{m}$ and 10 - to $15-\mu \mathrm{m}$ size classes of OPC (Figure 15). More interestingly, it shows that for large particles, $V_{\text {diff }}$ is nicely correlated with $u * u n t i l$ the wind friction velocity reaches about $33.5 \mathrm{~cm} / \mathrm{s}$ as can also be seen in Figure 14 . Once this value is exceeded, the dry deposition velocity drops very rapidly.

To estimate the fraction of rebound, we introduce the concept of "ideal

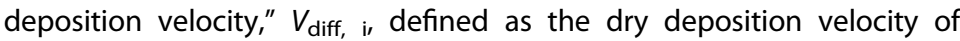
the particles if no rebound occurred. This ideal deposition velocity is obtained by extrapolating above $33.5 \mathrm{~cm} / \mathrm{s}$ the relationship linking $V_{\text {diff }}$ to $u_{*}$ for $u_{*}<33.5 \mathrm{~cm} / \mathrm{s}$. Then, a rough estimate of the fraction of rebound, $F_{\mathrm{R}}$, can be derived from the relative difference between $V_{\text {diff, i }}$ and $V_{\text {diff: }}$ :

$$
F_{\mathrm{R}}=\frac{V_{\text {diff,i }}-V_{\text {diff }}}{V_{\text {diff }, \mathrm{i}}}
$$

The results (Figure 16b) suggest that rebound could affect up to $80 \%$ of deposited (large) particles in the early morning and that this proportion decreased progressively to less than $20 \%$ around midday. This also explains why

1. only particles having a diameter lower than about $7.5 \mu \mathrm{m}$ are well correlated with $u_{*}$ all along the day,

2. the diffusive dry deposition velocity of particles $7.5-15 \mu \mathrm{m}$ is lower in the early morning than that of 3-5 $\mu \mathrm{m}$ particles (Figure 14), and

3. the deposition flux is mainly controlled by particles in the 3- to $7.5-\mu \mathrm{m}$ particle size range between 0737 and 0827 UTC (Figure 12) even though this is the period of the day during which large particles are most abundant.

Our estimates of the fraction of rebound deduced from the measurements are in quite good agreement with the experimental values obtained in wind tunnels by Wu et al. (1992b) for the rebound of 8.6- and 10- $\mu \mathrm{m}$ uranine particles or by Paw U (1983) for glass microbeads, Lycopodium spores, and ragweed pollen. They also confirm that rebound is zero when $u_{*}$ is below the critical rebound velocity in disagreement with equation (8).

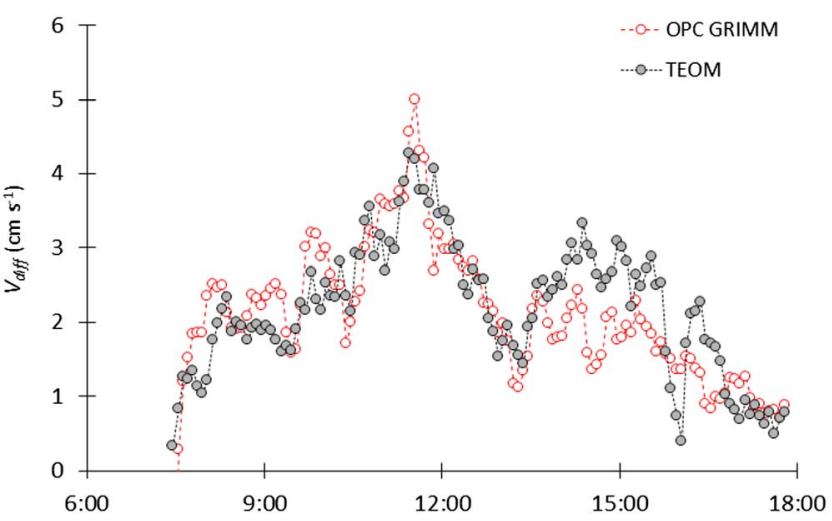

Figure 13. Diffusive dry deposition velocities derived from the tapered element oscillating microbalance (TEOM ${ }^{\oplus}$ gray circles) and optical particle counter (OPC; red circles) measurements for the 18 June 0727-1747 UTC period.

\subsection{Comparison With Dry Deposition Schemes}

As mentioned above, the dry deposition of particles involved different resistances that oppose to deposition. In most of the parameterizations, dry deposition is generally represented as a combination of these resistances in which gravitational settling operates in parallel to the other resistances that operate in series like in an electrical circuit (Hicks et al., 1987; Sehmel, 1980; Slinn, 1982; Wesely \& Hicks, 2000; Zhang et al., 2001). However, while this analogy of dry deposition to electrical resistances has many practical advantages, it does not satisfyingly represent the way by which the various deposition processes interact. Indeed, as mentioned in section 5.2.1, contrary to the other resistances that are concentration gradient dependent, gravitational settling is not and thus cannot be assimilated to a voltage. This has been clearly stated by Verkatram and Pleim (1999) who showed that the representation based on electrical analogy is not mass conservative even if it introduces only little difference in the estimations of the dry deposition velocities.

There is a general agreement on how the gravitational and aerodynamic resistances can be represented in dry deposition schemes. In fact, most of the dry deposition parameterizations differ on the parameterization of 


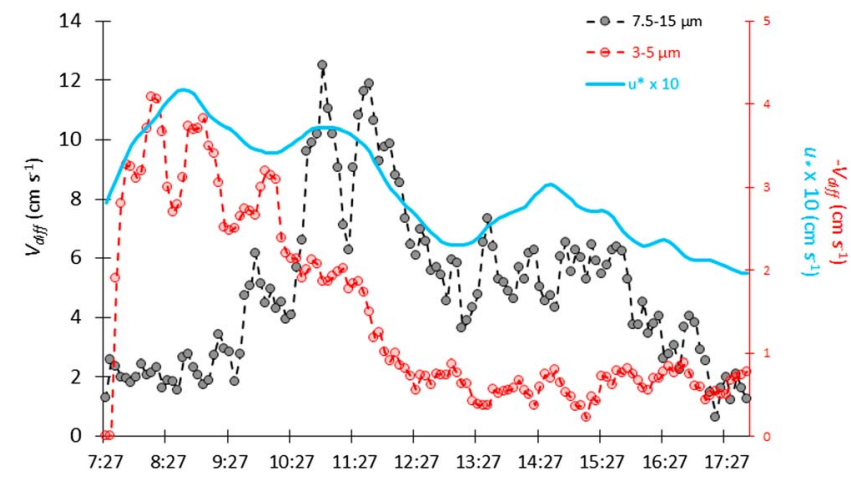

Figure 14. Diffusive dry deposition velocity of particles for the 3- to 5- $\mu \mathrm{m}$ (red circles) and 7.5- to $15-\mu \mathrm{m}$ (gray circles) particle size ranges and wind friction velocity (blue line) during 18 June 2006. the collection resistance on surfaces that are not totally smooth (e.g., Petroff \& Zhang, 2010; Slinn, 1982; Slinn \& Slinn, 1980; Zhang et al., 2001; Zhang \& Shao, 2014).

Recently, Zhang and Shao (2014) proposed a new deposition scheme in which (i) the dry deposition velocity is directly derived from the particle concentration equation and (ii) the surface collection process is accounted for by using the drag partition theory (e.g., Arya, 1975; Raupach, 1992; Shao \& Yang, 2005, 2008). One of the specifics of this parameterization that directly concerns deposition of dust particles is that desert bare surfaces (like sandy or silty soils) are not considered as totally smooth surfaces. This allows the interception of dust particles by micro-roughness elements, while interception is set to zero in most other dry deposition schemes that consider desert surfaces as smooth surfaces (e.g., Zhang et al., 2001). Moreover, dry deposition velocity measurements of dust particles were performed in wind tunnel over sandy, silty loam, and Gobi surfaces by the same team (Zhang et al., 2014) in order to serve as a basis for their parameterization.

Thus, we compared our in situ measurements to (i) the wind tunnel data obtained by Zhang et al. (2014) and to (ii) the dry deposition velocities predicted by the parameterizations of Zhang et al. (2001) and Zhang and Shao (2014). Indeed, as mentioned before, these dry deposition schemes are significantly different in the way by which both the deposition processes and their interaction are represented. We do not recall here the details of these parameterizations that are well described in the original papers.

The comparison is made on $V_{d}$, that is, $V_{\text {diff }}+V_{s}$, where $V_{s}$ is calculated according to equation (1) and added to the measured $V_{\text {diff. }}$

For applying these schemes, the values of some parameters need to be estimated. In the scheme proposed by Zhang et al. (2001), parameters or constants are ascribed to different land use categories. We selected for
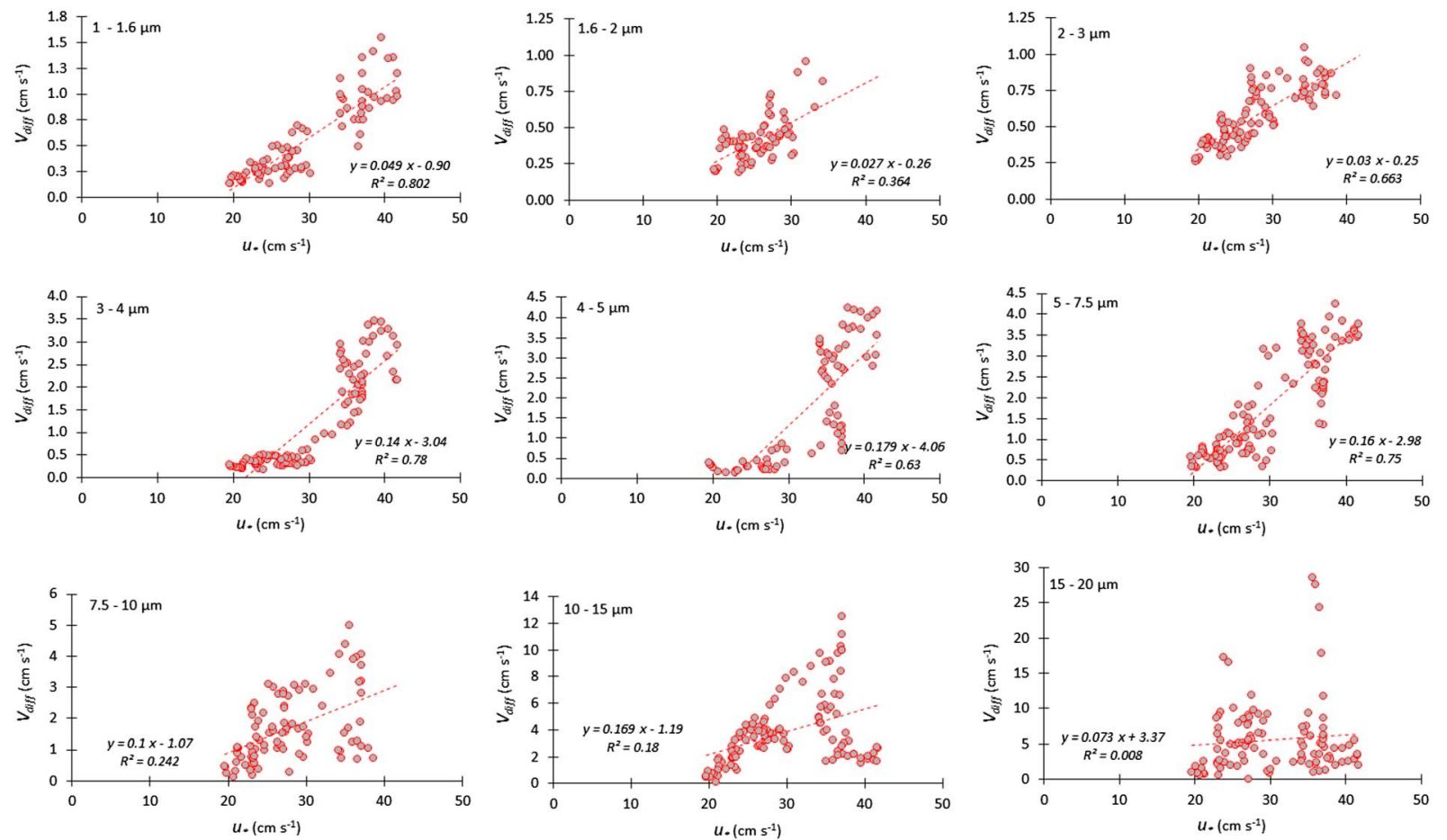

Figure 15. $V_{\text {diff }}$ versus $u_{*}$ for different size classes on 18 June 2006 (only $V_{\text {diff }}$ for which the difference between $C_{6.5}-C_{2.1}$ is $>5 \%$ are reported; Table $S 1$ in the supporting information provides the number of data used for each channel). 

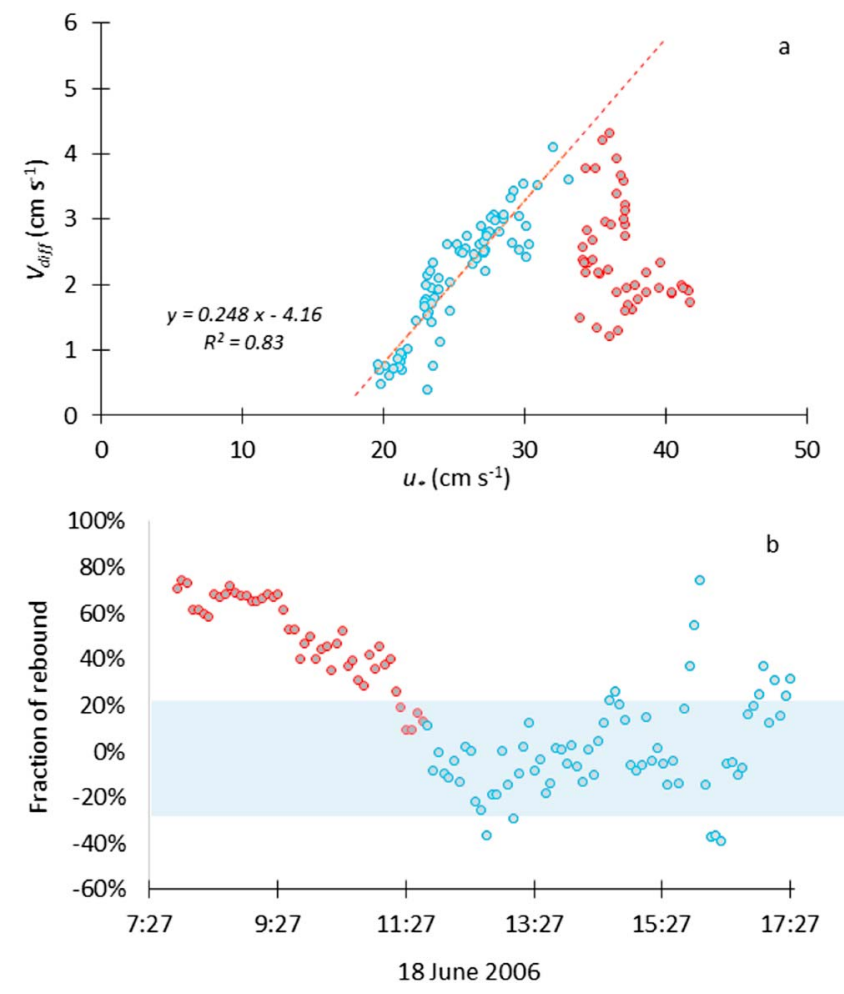

Figure 16. (a) Evolution of $V_{\text {diff }}$ derived from $\mathrm{TEOM}^{\circledR}$ measurements as a function of $u_{*}$ for $u_{*}<33.5 \mathrm{~cm} / \mathrm{s}$ (blue circles) and $u_{*}>33.5 \mathrm{~cm} / \mathrm{s}$ (red circles). (b) Fraction of rebound estimated as the relative difference between $V_{\text {diff }}$ deduced from measurements and $V_{\text {diff, i computed using the linear }}$ regression of Figure 16 .

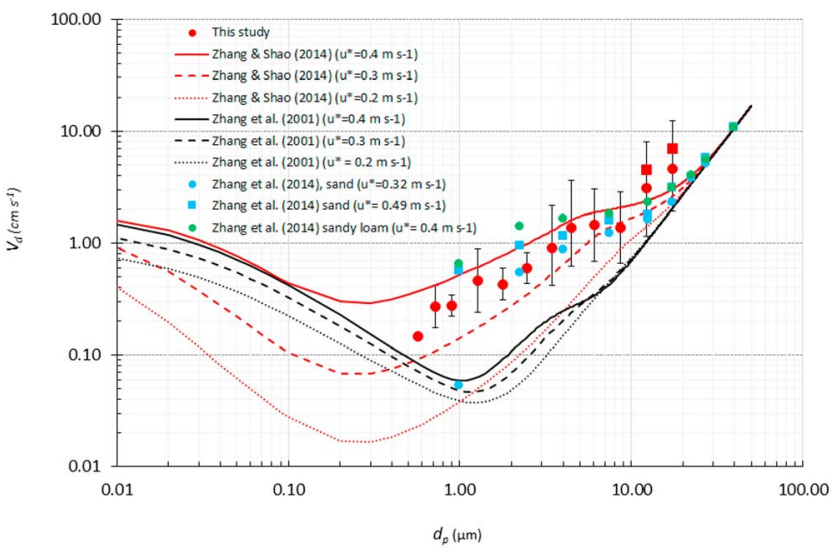

Figure 17. Comparison between measured dry deposition velocities (red circles) and the Zhang et al. (2001; black lines) and Zhang and Shao (2014; red lines) dry deposition schemes for three different wind friction velocities $(0.2,0.3$, and $0.4 \mathrm{~m} / \mathrm{s})$. For particles larger than $10 \mu \mathrm{m}$ in diameter, red circles correspond to the 0737-1002 UTC period and the red squares to the period 1007-1757 UTC. Only $V_{\mathrm{d}}$ for which the difference between $C_{6.5}$ and $C_{2.1}$ is $>5 \%$ are accounted for. Dry deposition velocities measured in a wind tunnel over sand (blue circles) and sandy loam (green circles) surfaces by Zhang et al. (2014) are also reported. these parameters or constants the values recommended for the "desert" (land use category 8) category, except for $z_{0}$ for which we used the value we measured in the field $(0.00076 \mathrm{~m}$, see section 5.1$)$. The Zhang and Shao (2014) scheme requires defining the height $\left(h_{c}\right)$ and the frontal area index $(\lambda)$ of the roughness elements. As for the application of the Zhang et al. (2001) scheme, we used the $z_{0}$ we measured in the field and then selected $a z_{0} / h_{c}$ ratio and $\lambda$ as close as possible to those reported by Zhang and Shao (2014) for their sand surface (1.35-1.5 and 0.125, respectively). Thus, we selected $h_{c}=6 \times 10^{-4} \mathrm{~m}$. Assuming as Zhang and Shao said that the obstacles are spherical and that $h_{c}$ is equal to half their diameter, $d_{c}$ leads to $\lambda=0.125$. Thus, with these assumptions, the obstacles on the field in Banizoumbou should have an averaged diameter of about $1.2 \times 10^{-3} \mathrm{~m}$, a reasonable estimate if we take into account the large dominance of coarse sand in the Banizoumbou soil (Lafon et al., 2014) and the low abundance of remaining crop residues.

For each scheme, the computations have been made assuming neutral stability conditions. Because the conditions were neutral or near neutral on 18 June 2006 (Figure 10), this choice has no impact on the comparison. The computations were performed for three different wind friction velocities $(0.2,0.3$, and $0.4 \mathrm{~cm} / \mathrm{s})$ covering roughly the range of wind friction velocities observed during the deposition event. The computations were made for $z=3.69 \mathrm{~m}$. For purpose of comparison, the wind tunnel data obtained by Zhang et al. (2014) were corrected for height using the method described in their paper.

Figure 17 shows that the measured dry deposition velocities are in good agreement with the dry deposition velocities measured in a wind tunnel by Zhang et al. (2014) over sand and sandy loam for wind friction velocities ranging between 0.3 and $0.49 \mathrm{~cm} / \mathrm{s}$. Our data also fit well with the Zhang and Shao (2014) scheme, especially for particles in the 0.6 - to $10-\mu \mathrm{m}$ particle size range, while the Zhang et al. (2001) scheme underestimates by almost 1 order of magnitude the dry deposition velocities for the same particle size range.

The better agreement observed with Zhang and Shao (2014) is due to the fact that this scheme treats bare sandy surfaces as slightly rough surfaces. This explains the increase of the deposition velocity in the 1 - to $10-\mu \mathrm{m}$ size range as compared to Zhang et al. (2001) who consider the desert surfaces as smooth surfaces and thus set the interception of particles to zero.

This strongly suggests that roughness elements present over the bare soil, even how small, favor significantly the interception of dust particles. Our in situ measurements confirm, in complement to the wind tunnel measurements of Zhang et al. (2014), that this approach accounts probably better for the processes occurring over bare soils than the Zhang et al. (2001) scheme does.

The dry deposition velocities measured for particles greater than $10 \mu \mathrm{m}$ are slightly higher than those both schemes predict. Because these particles were subjected to important rebound in the early morning when $u_{*}$ was the highest, we distinguished between data obtained for high and low $u_{*}$ (red circles and red squares, respectively; Figure 17). We observed that the dry deposition velocities of these particles are closer to the predictions of the dry deposition scheme for high $u_{*}$, that is, when the rebound is efficient. On the opposite, for lower $u_{*}$ the measured dry deposition velocities are significantly higher than those predicted by dry deposition 
schemes. In fact, equation (8) does not account for the existence of a critical velocity for rebound and thus generates rebound whatever the value of $u_{*}$. For example, in the Zhang and Shao (2014) scheme, rebound accounts for $30-40 \%$ for particles in the 10 - to $20-\mu \mathrm{m}$ particle size range even at low wind friction velocities $(\sim 0.2 / \mathrm{m} \mathrm{s})$. This increases the surface resistance and decreases the dry deposition velocity that tends toward the gravitational settling velocity. Our results clearly suggest that the parameterization of rebound in dry deposition schemes is not satisfying and should be reexamined.

\section{Conclusions}

A huge deposition event that occurred in Southwestern Niger in June 2006 was sampled over an almost bare surface. The large concentration gradients measured during this event allowed to use with a good confidence the flux gradient method to determine the diffusive deposition fluxes and associated dry deposition velocities. For that, we first compared the data obtained from instruments providing both the bulk and size-resolved deposition fluxes and found a good agreement between the two types of measurements. The stability conditions were neutral or near neutral almost all along the 10 hours the deposition event lasted.

The results show that the dust concentrations drive the diffusive dry deposition fluxes: deposition is maximum $\left(\sim 12 \mu \mathrm{g} \cdot \mathrm{m}^{-2} \cdot \mathrm{s}^{-1}\right)$ when the dust concentration is the highest $\left(\sim 900 \mu \mathrm{g} / \mathrm{m}^{3}\right)$. This is not the case for the dry deposition velocities. Indeed, for a given particle size class, the dry deposition velocities are mainly controlled by the dynamical conditions as scaled by the wind friction velocity. Indeed, dust particles smaller than $7.5 \mu \mathrm{m}$ in diameter follow quite well the temporal evolution of the wind friction velocity with higher diffusive dry deposition velocities observed when $u_{*}$ is the highest. For larger particles, the behavior is somewhat different: These particles follow the evolution of the wind friction velocity only when $u_{*}$ was below a threshold ( $33 \mathrm{~cm} / \mathrm{s}$ in our case). Above this value, the diffusive dry deposition velocity of large particles dropped sharply when $u_{*}$ increased: We show that the rebound is responsible for such an abrupt decrease of the dry deposition velocity of particles larger than $\sim 10 \mu \mathrm{m}$ in diameter. For these dust particles, rebound can be so important that their diffusive dry deposition velocity can become lower than that of medium-size dust particles. Moreover, our results suggest that the way by which rebound is accounted for in dry deposition parameterizations is not satisfying, especially because no threshold for rebound is introduced in the existing parameterization and that the dependence of rebound to $u_{*}$ is too smooth in this parameterization.

The dry deposition velocities we derive from our in situ measurements by summing the diffusive and gravitational deposition velocity are in good agreement with the wind tunnel measurements performed by Zhang et al. (2014). They confirm that dry deposition velocities of dust over bare soils is significantly greater in the 1- to $10-\mu \mathrm{m}$ size range than previously expected from "classical" dry deposition schemes. Thus, the comparison we performed between our in situ dry deposition velocities and two dry deposition schemes based on different modeling shows that only the Zhang and Shao (2014) scheme satisfyingly matches our in situ determinations of the dry deposition velocities for the 1- to $10-\mu \mathrm{m}$ particle size range. This good agreement is mainly due to a different parameterization of the surface collection resistance in this parameterization. In particular, the interception process accounts for the contribution of the micro-roughness elements present in the surface elements to the dust trapping. Our in situ results confirm the wind tunnel measurements performed by Zhang et al. (2014) that surfaces exhibiting low roughness like desert surfaces cannot be treated as smooth surfaces in regard to the dust dry deposition.

This enhancement of the dry deposition velocity compared to other existing deposition schemes is important because it represents at least half an order of magnitude for the 1- to $10-\mu \mathrm{m}$ size range that is by far the dominant size range of the dust mass size distribution.

Meteorological data used in Figures 2 and 9 were provided by the INDAAF

French national observation system. We also thanks J. Zhang and Y. Shao for the exchanges concerning their dry deposition parameterization. The data used in this manuscript are available for download for research and educational purposes at the web link http://www. lisa.univ-paris12.fr/fr/donnees maintained by Laboratoire Interuniversitaire des Systèmes Atmosphériques.

\section{References}

Abdourhamane Touré, A., Rajot, J. L., Garba, Z., Marticorena, B., Petit, C., \& Sebag, D. (2011). Impact of very low crop residues cover on wind erosion in the Sahel. Catena, 85(3), 205-214. https://doi.org/10.1016/j.catena.2011.01.002

Affre, C., Lopez, A., Carrara, A., Druilhet, A., \& Fontan, J. (2000). The analysis of energy and ozone flux data from the LANDES 94 experiment. Atmospheric Environment, 34(5), 803-821. https://doi.org/10.1016/S1352-2310(99)00295-2

Alfaro, S. C., Gomes, L., Rajot, J. L., Lafon, S., Gaudichet, A., Chatenet, B., et al. (2003). Chemical and optical characterization of aerosols measured in spring 2002 at the ACE-Asia supersite, Zhenbeitai, China. Journal of Geophysical Research, 108(D23), 8641. https://doi.org/ 10.1029/2002JD003214 
Anderson, T. L., \& Ogren, J. A. (1998). Determining aerosol radiative properties using the TSI 3563 integrating nephelometer. Aerosol Science \& Technology, 29(1), 57-69. https://doi.org/10.1080/0278682980 8965551

Arya, S. P. S. (1975). A drag partition theory for determining the large-scale roughness parameter and wind stress on the Arctic pack ice. Journal of Geophysical Research, 80(24), 3447-3454. https://doi.org/10.1029/JC080i024p03447

Bergametti, G., \& Foret, G. (2014). Dust Deposition. In P. Knippertz \& J. B. Stuut (Eds.), Mineral dust: A key player in the Earth system (Chap. 8 , pp. 179-200). Dordrecht, Netherlands: Springer. https://doi.org/10.1007/978-94-017-8978-3_8

Bergametti, G., Gomes, L., Remoudaki, E., Desbois, M., Martin, D., \& Buat-Ménard, P. (1989). Present transport and deposition patterns of African dusts to the north-western Mediterranean. In I. M. Leinen \& M. Sarnthein (Eds.), Paleoclimatology and Paleometeorology: Modern and Past Patterns of Global Atmospheric Transport (pp. 227-252). Dordrecht, Netherlands: Kluwer Academic. https://doi.org/10.1007/97894-009-0995-3_9

Bergametti, G., Marticorena, B., Rajot, J. L., Chatenet, B., Féron, A., Gaimoz, C., et al. (2017). Dust uplift potential in the central Sahel: An analysis based on 10 years of meteorological measurements at high temporal resolution. Journal of Geophysical Research: Atmospheres, 122, 12,433-12,448. https://doi.org/10.1002/2017JD027471

Bergametti, G., Rajot, J. L., Pierre, C., Bouet, C., \& Marticorena, B. (2016). How long does precipitation inhibit wind erosion in the Sahel? Geophysical Research Letters, 43, 6643-6649. https://doi.org/10.1002/2016GL069324

Bielders, C. L., Rajot, J. L., \& Michels, K. (2004). L'érosion éolienne dans le Sahel nigérien: Influence des pratiques culturales actuelles et méthodes de lutte. Sécheresse, 15, 19-32.

Businger, J. A. (1986). Evaluation of the accuracy with which dry deposition can be measured with current micrometeorological techniques. Journal of Climate and Applied Meteorology, 25(8), 1100-1124. https://doi.org/10.1175/1520-0450(1986)025<1100: EOTAWW $>2.0 . C O ; 2$

Chamberlain, A. C. (1966). Transport of gases to and from grass and grass-like surfaces. Proceedings of The Royal Society A Mathematical Physical and Engineering Sciences, 290(1421), 236-265. https://doi.org/10.1098/rspa.1966.0047

Chamberlain, A. C. (1967). Transport of Lycopodium spores and other small particles to rough surfaces. Proceedings of The Royal Society A Mathematical Physical and Engineering Sciences, 296(1444), 45-70. https://doi.org/10.1098/rspa.1967.0005

Chou, C., Formenti, P., Maille, M., Ausset, P., Helas, G., Harrison, M., \& Osborne, S. (2008). Size distribution, shape, and composition of mineral dust aerosols collected during the African Monsoon Multidisciplinary Analysis special observation period 0: dust and biomass-burning experiment field campaign in Niger, January 2006. Journal of Geophysical Research, 113, D00C10. https://doi.org/10.1029/2008JD009897

Davidson, C. I., \& Friedlander, S. K. (1978). A filtration model for aerosol dry deposition: Application to trace metal deposition from the atmosphere. Journal of Geophysical Research, 83(C5), 2343-2352. https://doi.org/10.1029/JC083iC05p02343

Duce, R. A., Liss, P. S., Merrill, J. T., Atlas, E. L., Buat-Ménard, P., Hicks, B. B., et al. (1991). The atmospheric input of trace species to the world ocean. Global Biogeochemical Cycles, 5(3), 193-259. https://doi.org/10.1029/91GB01778

Dupont, S., Rajot, J. L., Labiadh, M., Bergametti, G., Alfaro, S. C., Bouet, C., et al. (2018). Aerodynamic parameters over an eroding bare surface: Reconciliation of the law-of-the-wall and eddy-covariance determinations. Journal of Geophysical Research: Atmospheres, 123, 4490-4508. https://doi.org/10.1029/2017JD027984

Dyer, A. J., \& Hicks, B. B. (1970). Flux-gradient relationship in the constant flux layer. Quarterly Journal of the Meteorological Society, 96(410), 715-721. https://doi.org/10.1002/qj.49709641012

Figgis, B., Guo, B., Javed, W., Ahzi, S., \& Rémond, Y. (2018). Dominant environmental parameters for dust deposition and resuspension in desert climates. Aerosol Science \& Technology, 52(7), 788-798. https://doi.org/10.1080/02786826.2018.1462473

Foken, T. (2006). 50 years of the Monin-Obukhov similarity theory. Boundary-Layer Meteorology, 119(3), 431-447. https://doi.org/10.1007/ s10546-006-9048-6

Fowler, D., Pilegaard, K., Sutton, M. A., Ambus, P., Raivonen, M., Duyzer, J., et al. (2009). Atmospheric composition change: Ecosystemsatmosphere interactions. Atmospheric Environment, 43(33), 5193-5267. https://doi.org/10.1016/j.atmosenv.2009.07.068

Frangi, J. P., \& Richard, D. C. (2000). The WELSONS experiment: Overview and presentation of first results on the surface atmospheric boundary layer in semiarid Spain. Annales Geophysicae, 18(3), 365-384. https://doi.org/10.1007/s00585-000-0365-7

Gillette, D. A. (1977). Fine particulate emissions due to wind erosion. Transactions of the American Society of Agricultural Engineers, 20(5), 0890-0897. https://doi.org/10.13031/2013.35670

Giorgi, F. (1986). A particle dry deposition parameterization scheme for use in tracer transport models. Journal of Geophysical Research, 91(D9), 9794-9806. https://doi.org/10.1029/JD091iD09p09794

Golder, D. (1972). Relations among stability parameters in the surface layer. Boundary-Layer Meteorology, 3(1), 47-58. https://doi.org/ 10.1007/BF00769106

Goossens, D. (2010). Wind tunnel calibration of the USGS dust deposition sampler: Sampling efficiency and grain size correction. Aeolian Research, 2(2-3), 159-170. https://doi.org/10.1016/j.aeolia.2010.08.002

Greeley, R., Blumberg, D. G., McHone, J. F., Dobrovolski, A., Iversen, J., Lancaster, N., et al. (1997). Applications of space borne radar laboratory data to the study of aeolian processes. Journal of Geophysical Research, 102(E5), 10,971-10,983. https://doi.org/10.1029/97JE00518

Greeley, R., Gaddis, L., Lancaster, N., Dobrovolski, A., Iversen, J., Rasmussen, K., et al. (1991). Assessment of aerodynamic roughness via airborne radar observations. Acta Mechanica, 2(suppl), 77-88. https://doi.org/10.1007/978-3-7091-6703-8_6

Heimburger, A., Losno, R., Triquet, S., \& Bon Nguyen, E. (2013). Atmospheric deposition fluxes of 26 elements over the southern Indian Ocean Time series on Kerguelen and Crozet Islands. Global Biogeochemical Cycles, 27, 440-449. https://doi.org/10.1002/gbc.20043

Hicks, B. B. (1976). Wind profile relationships from the Wangara experiments. Quarterly Journal of the Royal Meteorological Society, 102(433), 535-551. https://doi.org/10.1002/qj.49710243304

Hicks, B. B., Baldocchi, D. D., Meyers, T. P., Hosker, R. P. Jr., \& Matt, D. R. (1987). A preliminary multiple resistance routine for deriving dry deposition velocities from measured quantities. Water, Air, and Soil Pollution, 36(3-4), 311-330. https://doi.org/10.1007/ BF00229675

Högström, U. L. F. (1988). Non-dimensional wind and temperature profiles in the atmospheric surface layer. Boundary-Layer Meteorology, 42 263-270. https://doi.org/10.1007/978-94-009-2935-7_6

Huneeus, N., Schulz, M., Balkanski, Y., Griesfeller, J., Prospero, J. M., Kinne, S., et al. (2011). Global dust model intercomparison in AeroCom phase I. Atmospheric Chemistry and Physics, 11(15), 7781-7816. https://doi.org/10.5194/acp-11-7781-2011

Kahn, T. R., \& Perlinger, J. A. (2017). Evaluation of five dry particle deposition parameterizations for incorporation into atmospheric transport models. Geoscientific Model Development, 10(10), 3861-3888. https://doi.org/10.5194/gmd-10-3861-2017

Kandler, K., Benker, N., Bundke, U., Cuevas, E., Ebert, M., Knippertz, P., et al. (2007). Chemical composition and complex refractive index of Saharan mineral dust at Izana, Tenerife (Spain) derived by electron microscopy. Atmospheric Environment, 41(37), 8058-8074. https://doi. org/10.1016/j.atmosenv.2007.06.047 
Klaver, A., Formenti, P., Caquineau, S., Chevaillier, S., Ausset, P., Calzolai, G., et al. (2011). Physico-chemical and optical properties of Sahelian and Saharan mineral dust: In situ measurements during the GERBILS campaign. Quarterly Journal of the Royal Meteorological Society, 137(658), 1193-1210. https://doi.org/10.1002/qj.889

Lafon, S., Alfaro, S. C., Chevaillier, S., \& Rajot, J. L. (2014). A new generator for mineral dust aerosol production from soil samples in the laboratory: Gamel. Aeolian Research, 15, 339-334. https://doi.org/10.1016/Kj.aeolia.2014.04.004

Laing, A. G., \& Fristch, J. M. (1993). Mesoscale convective complexes in Africa. Monthly Weather Review, 121(8), 2254-2263. https://doi.org/ $10.1175 / 15200493$

Lamaud, E., Chapuis, A., Fontan, J., \& Serie, A. (1994). Measurements and parameterization of aerosol dry deposition in a semi-arid area Atmospheric Environment, 28(15), 2461-2471. https://doi.org/10.1016/1352-2310(94)90397-2

Lancaster, N. (2004). Relation between aerodynamic and surface roughness in hyper-arid cold desert: McMurdo dry valleys, Antarctica. Earth Surface Processes and Landforms, 29(7), 853-867. https://doi.org/10.1002/esp.1073

Lettau, H. (1969). Note on aerodynamic roughness-parameter estimation on the basis of roughness-element description. Journal of Applied Meteorology, 8(5), 828-832. https://doi.org/10.1175/1520-0450(1969)008<0828:NOARPE $>2.0 . C O ; 2$

Lothon, M., Said, F., Lohou, F., \& Campistron, B. (2008). Observation of the diurnal cycle in the low troposphere of West Africa. Monthly Weather Review, 136(9), 3477-3500. https://doi.org/10.1175/2008MWR2427.1

Loÿe-Pilot, M. D., \& Martin, J. M. (1996). Saharan dust input to the western Mediterranean: An eleven years records in Corsica. In S. Guerzoni \& R. Chester (Eds.), The impact of desert dust across the Mediterranean (pp. 191-199). Dordrecht, Netherlands: Kluwer Academic. https://doi. org/10.1007/978-94-017-3354-0_18

Marsham, J. H., Parker, D. J., Grams, C. M., Taylor, C. M., \& Haywood, J. M. (2008). Uplift of Saharan dust south of the intertropical discontinuity. Journal of Geophysical Research, 113, D21102. https://doi.org/10.1029/2008JD009844

Marticorena, B., Bergametti, G., Aumont, B., Callot, Y., N’Doumé, C., \& Legrand, M. (1997). Modeling the atmospheric dust cycle: 2 . Simulation of Saharan sources. Journal of Geophysical Research, 102(D4), 4387-4404. https://doi.org/10.1029/96JD02964

Marticorena, B., Chatenet, B., Rajot, J. L., Bergametti, G., Deroubaix, A., Vincent, J., et al. (2017). Mineral dust over west and central Sahel: Seasonal patterns of dry and wet deposition fluxes from a pluriannual sampling (2006-2012). Journal of Geophysical Research: Atmospheres, 122, 1338-1364. https://doi.org/10.1002/2016JD025995

Marticorena, B., Kardous, M., Bergametti, G., Callot, Y., Chazette, P., Khatteli, H., et al. (2006). Aeolian geometric and aerodynamic surface roughness in arid and semi-arid areas and their relation with radar backscatter coefficient. Journal of Geophysical Research, 111, F03017. https://doi.org/10.1029/2006FJ000462

Monin, A. S., \& Obukhov, A. M. (1954). Basic laws of turbulent mixing in the atmosphere near the ground. Trudy Geofizicheskogo Instituta, Akademiya Nauk SSSR, 24, 1963-1987.

Nickling, W. G., \& Gillies, J. A. (1989). Emission of fine-grained particulates from desert soils. In M. Leinen \& M. Sarnthein (Eds.), Paleoclimatology and Paleometeorology: Modern and Past Patterns of Global Atmospheric Transport (pp. 135-169). Dordrecht, Netherlands: Kluwer Academic. https://doi.org/10.1007/978-94-009-0995-3_5

Panofsky, H. A., \& Dutton, J. A. (1984). Atmospheric turbulence: Models and methods for engineering applications (p. 397). New York: John Wiley.

Patashnick, H., \& Rupprecht, E. G. (1991). Continuous PM-10 measurements using the tapered element oscillating microbalance. Journal of the Air and Waste Management Association, 41(8), 1079-1083. https://doi.org/10.1080/10473289.1991.10466903

Paulson, C. A. (1970). The mathematical representation of wind speed and temperature profiles in the unstable atmospheric surface layer Journal of Applied Meteorology, 9(6), 857-861. https://doi.org/10.1175/1520-0450(1970)009<0857:TMROWS $>2.0 . C O ; 2$

Paw, U, K. T. (1983). The rebound of particles from natural surfaces. Journal of Colloid and Interface Science, 93(2), 442-452. https://doi.org/ 10.1016/0021-9797(83)90428-9

Paw U, K. T., \& Braaten, D. A. (1992). Experimental evidence of the importance of rebound in net deposition of particles. Aerosol Science and Technology, 17(4), 278-288. https://doi.org/10.1080/02786829208959576

Petroff, A., Mailliat, A., Amielh, M., \& Anselmet, F. (2008). Aerosol dry deposition on vegetative canopies. Part I: Review of present knowledge. Atmospheric Environment, 42(16), 3625-3653. https://doi.org/10.1016/j.atmosenv.2007.09.043

Petroff, A., \& Zhang, L. (2010). Development and validation of a size-resolved particle dry deposition scheme for application in aerosol transport models. Geoscientific Model Development, 3(2), 753-769. https://doi.org/10.5194/gmd-3-753-2010

Porch, W. M., \& Gillette, D. A. (1977). A comparison of aerosol and momentum mixing in dust storms using fast-response instruments. Journal of Applied Meteorology, 16(12), 1273-1281. https://doi.org/10.1175/1520-0450(1977)016<1273:ACOAAM >2.0.CO;2

Prospero, J. M., Landing, W. M., \& Schulz, M. (2010). African dust deposition to Florida: Temporal and spatial variability and comparisons to models. Journal of Geophysical Research, 115, D13304. https://doi.org/10.1029/2009JD012773

Rajot, J. L. (2001). Wind-blown sand mass budget of Sahelian village land units in Niger. Bulletin de la Société Géologique de France, 172(5), 523-531. https://doi.org/10.2113/172.5.523

Rajot, J. L., Formenti, P., Alfaro, S., Desboeufs, K., Chevaillier, S., Chatenet, B., et al. (2008). AMMA dust experiment: An overview of measurements performed during the dry season special observation period (SOP0) at the Banizoumbou (Niger) supersite. Journal of Geophysical Research, 113, D00C14. https://doi.org/10.1029/2008JD009906

Raupach, M. (1992). Drag and drag partition on rough surfaces. Boundary-Layer Meteorology, 60(4), 375-395. https://doi.org/10.1007/ BF00155203

Roberts, A. J., \& Knippertz, K. (2012). Haboobs: Convectively generated dust storms in West Africa. Weather, 67(12), 311-316. https://doi.org/ 10.1002/wea.1968

Rolph, G. D., Stein, A. F., \& Stunder, B. J. B. (2017). Real-time Environmental Applications and Display sYstem: READY. Environmental Modelling \& Software, 95, 210-228. https://doi.org/10.1016/j.envsoft. 2017.06.025

Rossby, C. G., \& Montgomery, R. B. (1935). The layer of frictional influence in wind and ocean currents, Papers in Physical Oceanography and Meteorology, III-3, Published by Massachusetts Institute of Technology and Woods Hole Oceanographic Institution (101 pp.). https://doi. org/10.1575/1912/1157

Schütz, L. (1979). Saharan dust transport over the North-Atlantic Ocean-Model calculations and measurements. In C. Morales (Ed.), Saharan dust. SCOPE 14 (Chap. 14, pp. 267-277). New York: John Wiley.

Sehmel, G. A. (1980). Particle and gas dry deposition: A review. Atmospheric Environment, 14(9), 983-1011. https://doi.org/10.1016/0004 $6981(80) 90031-1$

Shao, Y. (2008). Physics and modelling of wind erosion (2nd and revised ed. p. 452). Berlin: Springer.

Shao, Y., \& Yang, Y. (2005). A scheme for drag partition over rough surfaces. Atmospheric Environment, 39(38), 7351-7361. https://doi.org/ 10.1016/j.atmosenv.2005.09.014 
Shao, Y., \& Yang, Y. (2008). A theory of drag partition over rough surfaces. Journal of Geophysical Research, 113, F02S05. https://doi.org/ 10.1029/2007JF000791

Slinn, S. A., \& Slinn, W. G. N. (1980). Predictions for particle deposition on natural waters. Atmospheric Environment, 14(9), 1013-1016. https:// doi.org/10.1016/0004-6981(80)90032-3

Slinn, W. G. N. (1982). Predictions for particle deposition to vegetative canopies. Atmospheric Environment, 16(7), 1785-1794. https://doi.org/ 10.1016/0004-6981(82)90271-2

Sow, M., Alfaro, S. C., Rajot, J. L., \& Marticorena, B. (2009). Size resolved dust emission fluxes measured in Niger during 3 dust storms of the AMMA experiment. Atmospheric Chemistry and Physics, 9(12), 3881-3891. https://doi.org/10.5194/acp-9-3881-2009

Sow, M., Goossens, D., \& Rajot, J.-L. (2006). Calibration of the MDCO dust collector and of four versions of the inverted Frisbee dust deposition sampler. Geomorphology, 82(3-4), 360-375. https://doi.org/10.1016/j.geomorph.2006.05.013

Spaan, W. P., \& van den Abeeleb, G. D. (1991). Wind borne particle measurements with acoustic sensors. Soil Technology, 4(1), 51-63. https:// doi.org/10.1016/0933-3630(91)90039-P

Stein, A. F., Draxler, R. R., Rolph, G. D., Stunder, B. J. B., Cohen, M. D., \& Ngan, F. (2015). NOAA's HYSPLIT atmospheric transport and dispersion modeling system. Bulletin of the American Meteorological Society, 96(12), 2059-2077. https://doi.org/10.1175/BAMS-D-14-00110.1

Stull, R. B. (1988). An introduction to boundary layer meteorology (666 pp.). Dordrecht, Netherlands: Kluwer Academic Publishers. https://doi. org/10.1007/978-94-009-3027-8

Textor, C., Schulz, M., Guibert, S., Kinne, S., Balkanski, Y., Bauer, S., et al. (2007). The effect of harmonized emissions on aerosol properties in global models-An AeroCom experiment. Atmospheric Chemistry and Physics, 7(17), 4489-4501. https://doi.org/10.5194/acp-7-4489-2007

Jetmatsu, M., Duce, R. A., \& Prospero, J. M. (1985). Deposition of atmospheric mineral dust in the North-Pacific Ocean. Journal of Atmospheric Chemistry, 3(1), 123-138. https://doi.org/10.1007/BF00049372

Verkatram, A., \& Pleim, J. (1999). The electrical analogy does not apply to modeling dry deposition of particles. Atmospheric Environment, 33(18), 3075-3076. https://doi.org/10.1016/S1352-2310(99)00094-1

Vincent, J., Laurent, B., Losno, R., Bon Nguyen, E., Roullet, P., Sauvage, S., et al. (2016). Variability of mineral dust deposition in the Western Mediterranean basin and southeast of France. Atmospheric Chemistry and Physics, 16(14), 8749-8766. https://doi.org/10.5194/acp-168749-2016

Webb, E. K. (1970). Profile relationships: The log-linear range, and extension to strong stability. Quarterly Journal of the Royal Meteorological Society, 96(407), 67-90. https://doi.org/10.1002/qj.49709640708

Wesely, M. L., Cook, D. R., Hart, R. L., \& Speer, R. E. (1985). Measurements and parameterization of particulate sulfur dry deposition over grass. Journal of Geophysical Research, 90(D1), 2131-2143. https://doi.org/10.1029/JD090iD01 p02131

Wesely, M. L., \& Hicks, B. B. (2000). A review of the current status of knowledge on dry deposition. Atmospheric Environment, 34(12-14), 2261-2282. https://doi.org/10.1016/S1352-2310(99)00467-7

Wieringa, J. (1993). Representative roughness parameters for homogeneous terrains. Boundary-Layer Meteorology, 63(4), 323-363. https:// doi.org/10.1007/BF00705357

Wu, Y. L., Davidson, C. I., \& Russell, A. G. (1992a). A stochastic model for particle deposition and bounce-off. Aerosol Science and Technology 17(4), 231-244. https://doi.org/10.1080/02786829208959573

Wu, Y. L., Davidson, C. I., \& Russell, A. G. (1992b). Controlled wind tunnel experiments for particle bounce off and resuspension. Aerosol Science and Technology, 17(4), 245-262. https://doi.org/10.1080/02786829208959574

Xian, X., Tao, W., Qingwei, S., \& Weimin, Z. (2002). Field and wind-tunnel studies of aerodynamic roughness length. Boundary-Layer Meteorology, 104(1), 151-163. https://doi.org/10.1023/A:1015527725443

Yudine, M. I. (1959). Physical considerations on heavy-particle diffusion. Advances in Geophysics, 6, 185-191. https://doi.org/10.1016/S00652687(08)60106-5

Zhang, J., \& Shao, Y. (2014). A new parameterization of particle dry deposition over rough surfaces. Atmospheric Chemistry and Physics, 14(22) 12,429-12,440. https://doi.org/10.5194/acp-14-12429-2014

Zhang, J., Shao, Y., \& Huang, N. (2014). Measurements of dust deposition velocity in a wind tunnel experiment. Atmospheric Chemistry and Physics, 14(17), 8869-8882. https://doi.org/10.5194/acp-14-8869-2014

Zhang, L., Gong, S., Padro, J., \& Barrie, L. (2001). A size-segregated particle dry deposition scheme for an atmospheric aerosol module. Atmospheric Environment, 35(3), 549-560.

Zhang, L., \& He, Z. (2014). Technical note: An empirical algorithm estimating dry deposition velocity of fine, coarse and giant particles. Atmospheric Chemistry and Physics, 14(7), 3729-3737. https://doi.org/10.5194/acp-14-3729-2014 